\title{
REVIEW
}

\section{$b$-Values Observations in Taiwan: A Review}

\author{
Jeen-Hwa Wang ${ }^{1, *}$, Kou-Cheng Chen ${ }^{1}$, Pei-Ling Leu ${ }^{2}$, and Jeng-Hsin Chang ${ }^{2}$ \\ ${ }^{1}$ Institute of Earth Sciences, Academia Sinica, Taipei, Taiwan, R.O.C. \\ ${ }^{2}$ Seismological Center, Central Weather Bureau, Taipei, Taiwan, R.O.C.
}

Received 5 January 2015, revised 1 April 2015, accepted 28 April 2015

\begin{abstract}
High seismicity with spatial heterogeneity in Taiwan makes this region one of the best natural laboratories for seismological researches. Numerous seismicity studies, including the $b$-value, have been performed for more than one century. One of the possible ways to mitigate seismic risk is predicting an impending earthquake through various kinds of seismic precursors observations. The first seismic precursors project in Taiwan started in 1978. The temporal variation in $b$-value prior to a forthcoming earthquake has been considered a significant seismic precursor for earthquake prediction. In this review study, we focus on the studies of $b$-values of earthquakes in Taiwan, including the spatial distribution of $b$-values, temporal variation in $b$-values, correlation between the $b$-value and fractal dimension, and correlation between the $b$ - and p-value of Omori law for aftershocks. Also included is the relation between the spatial distribution of $b$-values and regional geotectonics. The properties and controlling factors of $b$-value and earthquake monitoring in Taiwan will also be briefly described.
\end{abstract}

Key words: Gutenberg-Richter frequency-magnitude law, $b$-value, p-value, Fractal dimension

Citation: Wang, J. H., K. C. Chen, P. L. Leu, and J. H. Chang, 2015: b-values observations in Taiwan: A review. Terr. Atmos. Ocean. Sci., 26, 475-492, doi: 10.3319/TAO.2015.04.28.01(T)

\section{INTRODUCTION}

A scaling law states that two quantities are proportional to each other and is valid at certain orders of magnitude. This can be used to calculate the value of one of the quantities at another order of magnitude. A scaling law usually has a power-law form. In earthquake seismology, Gutenberg and Richter (1944) proposed a frequency-magnitude (FM) relationship for earthquakes in the form: $\log \mathrm{N}=\mathrm{a}-\mathrm{bM}$ where $\mathrm{M}$ is the earthquake magnitude and $\mathrm{N}$ is the discrete frequency of events with magnitudes in a small range for $M$ to $M+\delta M$ or the cumulative frequency of events with magnitudes $\geq \mathrm{M}$. This relationship is denoted by the GR law hereafter. An example of the FM distribution is displayed in Fig. 1. The GR law is valid in the magnitude range between $M_{1}$ and $\mathrm{M}_{2}$, which are the lower and upper bounds of the linear portion. Although the $b$-value varies from area to area and is also dependent upon the time interval of earthquake data in

\footnotetext{
* Corresponding author

E-mail:jhwang@earth.sinica.edu.tw
}

use, its values generally vary from $0.8-1.2$. This law works for natural earthquakes and for different kinds of fractures, including faults (e.g., Otsuki and Dilov 2005), laboratory rock mechanics experiments (e.g., Weeks et al. 1978; Sammonds and Ohnaka 1998), fractures caused by hydrocarbon recovery (e.g., Lahaie and Grasso 1999), mining-induced seismicity (e.g., Holub 1996), volcanic earthquakes (e.g., Wiemer and McNutt 1997) and so on.

The GR's FM law can be re-written as $\mathrm{N}(\mathrm{M})=\mathrm{C} 10^{-\mathrm{bM}}$ $=\mathrm{Ce} \mathrm{e}^{\mathrm{M} / \beta}$, where $\mathrm{C}=10^{\mathrm{a}}$ and $\beta=\mathrm{b} / \log (\mathrm{e})=\mathrm{b} / 0.4343$. Obviously, this is an exponential function rather than a powerlaw function. We can present scaling-law behavior for the GR law from three different approaches. First, based on the peak amplitude, $\mathrm{A}$, of a seismogram we have $\mathrm{M} \sim \gamma \log (\mathrm{A})$, thus leading to $N \sim A^{-\alpha}$, where $\alpha=\gamma b$. Secondly, from the seismic moment, $\mathrm{M}_{\mathrm{o}}$, we have $\mathrm{M} \sim \eta \log \left(\mathrm{M}_{\mathrm{o}}\right)$, thus giving $\mathrm{N} \sim \mathrm{M}_{\mathrm{o}}^{-\mathrm{m}}$, where $\mathrm{m}=\eta \mathrm{b}$. Thirdly, the seismic energy, $\mathrm{E}$, released during an earthquake is related to $\mathrm{M}$ in the form: $\log \mathrm{E} \sim \xi \mathrm{M}$, where $\xi$ is 1 and $3 / 2$ for small and large earthquakes, respectively (Ekström and Dziewonski 1988). N 
therefore relates to $\mathrm{E}$ in the form: $\mathrm{N} \sim \mathrm{E}^{-\mathrm{B}}$, where $\mathrm{B}=\mathrm{b} / \xi$. The three approaches obviously lead to respective powerlaw scaling to characterize seismicity.

In order to examine the effect on $\mathrm{N}$ due to a change in $\mathrm{M}$, we take the derivative of $\log [\mathrm{N}(\mathrm{M})]$ with relative to $\mathrm{M}$, that is, $d[\log (\mathrm{N})] / \mathrm{dM}=-\mathrm{b}$. This indicates that $\mathrm{d}[\log (\mathrm{N})] / \mathrm{dM}$ is independent of N. Since $d[\log (N)] / d M=(d N / d M) / N$, we have $\mathrm{dN} / \mathrm{dM}=-\mathrm{bN}$. Obviously, $\mathrm{dN} / \mathrm{dM}$ is a function of $\mathrm{N}$. Considering an increase in $\mathrm{M}$, i.e., $\mathrm{dM}>0$, the number of events decreases, i.e., $\mathrm{dN}=-\mathrm{bNdM}<0$. Considering a decrease in $\mathrm{M}$, i.e., $\mathrm{dM}<0$, the number of events increases, i.e., $\mathrm{dN}=-\mathrm{bNdM}>0$.

The function $\mathrm{F}(\mathrm{M})$ is defined as the cumulative probability distribution of earthquakes with magnitudes $\geq \mathrm{M}$, we have $\log [1-\mathrm{F}(\mathrm{M})]=\log \left[\mathrm{N}(\mathrm{M}) / \mathrm{N}_{\mathrm{o}}\right]$ where $\mathrm{N}_{\mathrm{o}}=10^{\mathrm{a}}$ is the total events in consideration. This gives $\mathrm{F}(\mathrm{M})=1-\exp (-\beta \mathrm{M})$. The function $\mathrm{f}(\mathrm{M})$ is defined as the single probability (or frequency) distribution of an earthquake with a magnitude within $\mathrm{M}$ and $M+\delta M$, we have $f(M)=d F(M) / d M=\beta \exp (-\beta M)$. Let $M^{*}$ be the magnitude when $N\left(M^{*}\right)=1$, i.e., $M^{*}=a / b$, and $\mathrm{N}(\mathrm{M})$ the number of earthquakes with magnitudes $\geq \mathrm{M}$ in a time period. Thus the return period of such events is $T_{M}$ $=1 / \mathrm{N}(\mathrm{M})=10^{-\mathrm{b}\left(\mathrm{M}^{*} \mathrm{M}\right)}$. The $b$-value or the $\beta$-value therefore plays an important role on seismic hazard assessment.

There are two common methods to calculate the $b$-value. In the first method, the $b$-value is the slope value of the linear portion of data points of $\log (\mathrm{N})$ versus $\mathrm{M}$ in the range between $\mathrm{M}_{1}$ and $\mathrm{M}_{2}$ using the common least-squared method. In the second method, the $b$-value is calculated from the formula: $b=\log (e) /\left(M_{a}-M_{1}\right)$, where $M_{a}$ is the average magnitude, proposed by Aki (1965) based on the maximum likelihood principle. In general, the stability of evaluating the $b$-value is higher from the second method than from the first. From practical calculations Knopoff (2000) found that when $\mathrm{M}_{1}$ is fixed, the maximum likelihood estimate of $b$ value is a function of the variable upon $\mathrm{M}_{2}$ and the calculation stability increases with $\mathrm{M}_{2}$. Of course, the choice of $\mathrm{M}_{1}$ also influences the estimate of $b$-value.

One of the significant ways to mitigate seismic risk is predicting a forthcoming earthquake through the observations of precursors together with physical modeling. Earthquake prediction research has generally been an important issue in countries that are frequently attacked by large earthquakes (Chen et al. 1992; Aki 1995; Knopoff 1996). Of course, some seismologists (e.g., Geller 1997; Geller et al. 1997) argued the low possibility of predicting an earthquake. Actually, to date the success rate in predicting an earthquake is still very low. The temporal variation in $b$-value could be a significant precursor for volcano activities and earthquake occurrences. Gorshkov first observed a decrease in $b$-value before the Russian Bezymianny eruption in 1956 (see Aki 1985). Suyehiro (1966) first found a change in the $b$-value before and after an earthquake. Knopoff et al. (1982) also observed a similar phenomenon. Fiedler (1974) first found an increase in $b$-value before the 1967 Caracas earthquake. Numerous studies also exhibit an increase in $b$ value prior to an earthquake ( $\mathrm{Li}$ et al. 1978; Smith 1981, 1986; Wyss et al. 1981; Chen et al. 1984a, b; Kiek 1984; Aki 1985; DasGupta et al. 2007, 2012; Moatti et al. 2013). Chen et al. (1984b) also found that the occurrence times and magnitudes of high $b$-values are area-dependent.

After analyzing the data from various earthquake precursors amounting to 418 in number accumulated in Japan, Rikitake $(1975,1987)$ proposed a formula to relate the occurrence time, $\mathrm{T}$ (in days), of a precursor to the magnitude, $\mathrm{M}$, of the forthcoming earthquake, that is $\log (\mathrm{T})=-1.83+0.76 \mathrm{M}$. Indeed, he mentioned that different groups of precursors obtained different $T$ versus $M$ relationships. A linear relation such as: $\log (\mathrm{T})=\mathrm{q}+\mathrm{rM}$ where $\mathrm{q}$ and $\mathrm{r}$ are the constants, seems to hold for precursor disciplines such as land deformation revealed by geodetic survey and tide-gauge observation, ground tilt observed by a water-tube tiltmeter, anomalous seismic activity and geomagnetic field changes.

Within the vicinity of forthcoming large earthquakes, Smith (1981) observed an increase in $b$ and then a return to normal. He related the precursor time, $\mathrm{T}$ (in days), to the earthquake magnitude, $\mathrm{M}$, in the following form: $\log (\mathrm{T})=1.42+0.30 \mathrm{M}$. From his Table 1 , we can see the abnormal $b$-value appears, at least, about one year before the forthcoming earthquake when $M \geq 4$. Obviously, the value of $\mathrm{T}$ is longer from this formula than from Rikitake's. This difference might be due to two reasons: the first reason is that the two formulas were inferred from earthquakes occurring in different regions: Rikitake's from Japanese earthquakes and Smith's from New Zealand events. The precursor time could vary area to area. The second reason is that Rikitake's relationship was made from all kinds of precursors that he collected and Smith's only from the $b$ value anomaly. Let T' be the time prior to the forthcoming earthquake when the $b$-value returns to normal. Hence, T' is the waiting time for the forthcoming earthquake after the

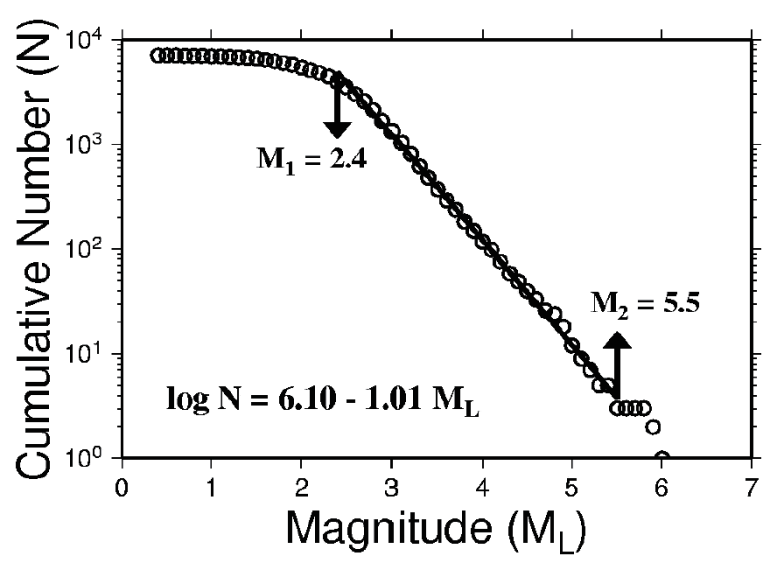

Fig. 1. Examples of the plots of $\log (\mathrm{N})$ versus $\mathrm{M}$ for earthquakes occurring in northern Taiwan. 
abnormally high $b$-value begins to decrease. For seven New Zealand earthquakes with $5.40 \leq \mathrm{M} \leq 6.33$, Smith (1986) found $\mathrm{T}^{\prime}=0.24\left(\mathrm{~T}-\mathrm{T}^{\prime}\right)$ or $\mathrm{T}^{\prime}=0.19 \mathrm{~T}$, where $\mathrm{T}-\mathrm{T}^{\prime}$ is the time interval specified with high $b$-values.

On the other hand, there have been opposite observations. Weeks et al. (1978) found that the $b$-value decreases prior to large slip in rock mechanics experiment using dry rock. Wyss and Lee (1973) observed a decrease in $b$-value before several earthquakes in California. Chen et al. (1984b) observed a decrease in $b$-value before the M 7.1 Zhao-tong earthquake of 11 May 1974. Nanjo et al. (2012) observed a decrease in $b$-value in the source regions prior to the 2004 M 9.2 Sumatra and 2011 M 9 Tohoku earthquakes. Their observations were different from those by DasGupta et al. (2007). Schurr et al. (2014) observed a decrease in $b$-value in the source regions prior to the M 8.1 Iquique, Northern Chile, earthquake of 1 April 2014.

Taiwan is located at the juncture of the Eurasian plate and the Philippine Sea plate (Tsai et al. 1977; Wu 1978; Tsai 1986; Lin 2002). The Philippine Sea plate has been moving northwestward at a speed of $\sim 80 \mathrm{~mm} \mathrm{year}^{-1}$ (Yu et al. 1997) to collide with the Eurasian plate. The Okinawa Trough has extended southwestward to approach Taiwan (Eguchi and Uyeda 1983). Active orogeny due to the collision of the two plates causes complex geological features and high seismicity in the region (from $119-123^{\circ} \mathrm{E}$ and $21-26^{\circ} \mathrm{N}$ ). The complex tectonics in the region result in a non-uniform spatial distribution of earthquakes (Wang et al. 1983, 1994; Wang 1988, 1998; Wang and Shin 1998). For a detailed explanation of regional geology, readers are advised to refer to Ho (1975). Only a simple description is given here. Generally speaking, the region can be divided into two major tectonic provinces, separated by a narrow, linear feature known as the Taitung Longitudinal Valley. The fault in the valley strikes approximately $\mathrm{N} 20^{\circ} \mathrm{E}$ (almost parallel to the valley) and dips $70^{\circ}$ to the east. It is a left-lateral oblique thrust fault. The eastern province, comprising the Coastal Range and the two small islands of Lu-Tao and Lan-Hsu, is a remnant Neogene island arc. The western province is a deformed micro-geosyncline with Cenozoic sediments more than $10 \mathrm{~km}$ thick deposited on top of a pre-Tertiary metamorphic basement. This province is usually divided into numerous units. From east to west, the main units are (1) the Central Range, subdivided into the East and West Ranges; (2) the Western Foothills; and (3) the Coastal Plains and Terraces. The Tatun Volcano Group (TVG) is in northern Taiwan.

High and heterogeneous seismicity in Taiwan makes the region serve as one of the best natural laboratories for seismological studies. Hence, seismicity studies have been performed in Taiwan for more than a century (Wang 1998; Wang and Shin 1998). For a detailed description concerning seismicity studies, including the $b$-value, performed before 1998 see Wang $(1992,1998)$.

Earthquake prediction has received great attention by
Taiwan's Earth scientists since the Taiwan Telemetered Seismographic Network (TTSN) installation. Tsai et al. (1983) reviewed the earthquake prediction researches performed in the region before 1983 . However, the temporal variation in $b$-value was not included in their review paper. The researches on seismic precursors in Taiwan began in 1978 . Since then several projects for seismic precursors sponsored by the Ministry of Science and Technology (formerly the National Science Council), Central Geological Surveys, Central Weather Bureau (CWB) have been conducted by different units and individuals over a long time period. Yang (1986) reviewed the studies on some seismic precursors.

In this review work, we focus on the studies of $b$-values of earthquakes in Taiwan, including the spatial distributions of $b$-values, $b$-values for individual earthquakes, temporal variations in $b$-values, correlation between the $b$-value and fractal dimension, and correlation between the $b$-value and p-value of Omori's (1894) law for aftershocks. Noted that the data for the correlation b versus $\mathrm{p}$ are not limited to Taiwan's earthquakes, because the $\mathrm{p}$-values were measured for only a few events in the region. Noted that the $b$-value observations given in some technical reports for engineering purposes are not included in the review article. Included also in this review article are the properties and controlling factors of the $b$-value. Earthquake monitoring in Taiwan will also be briefly described for those who are not familiar with this matter.

\section{PROPERTIES AND CONTROLLING FACTORS OF $b$-VALUE}

Figure 2 shows three types of FM distributions that will be explained below. Figures 1 and 2 exhibit that the observed number of events with magnitudes $<\mathrm{M}_{1}$ is usually very small. This phenomenon can be seen for natural earthquakes and for

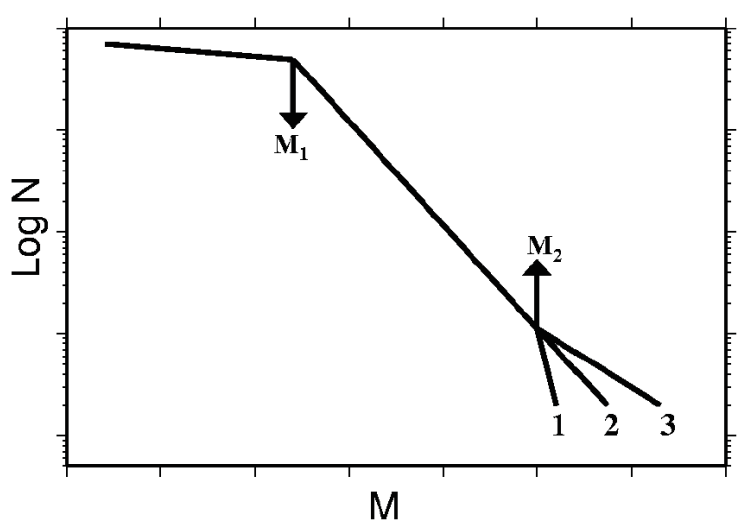

Fig. 2. Three types of frequency-magnitude (FM) distribution $\left(\mathrm{M}_{1}=\right.$ the lower bound for the GR's FM law and $\mathrm{M}_{2}=$ the lower bound for the GR's FM law): for line 1, the number of larger-sized events is smaller than the predicted from the GR's FM law; for line 2, the number of larger-sized events is predicted from the GR's FM law; for line 3 , the number of larger-sized events is larger than the predicted from the GR's FM law. 
mine bursts (Holub 1996). This departure has traditionally been attributed to a deficit of data recorded within a short time period or due to the detection threshold of the recording network caused by cultural noise and winds (Rydelek and Sacks 1989). Under these assumptions, a large number of micro- and small earthquakes which indeed occur are not detected. On the other hand, some recent studies (e.g., Abercrombie 1996) suggested that this reduction, compared to that expected from a constant $b$-value, is not just an artifact of the recording system, but that there really are fewer small earthquakes than self-similarity predicts. Aki (1987) determined magnitudes for earthquakes recorded in a $1.5 \mathrm{~km}$ borehole in southern California and found a decrease in the $b$-value below $\mathrm{M}=2$, but calculated that the catalogue was complete above $\mathrm{M}=0$. From the observed seismicity in Hokkaido and northeastern Japan, respectively, Taylor et al. (1990) and Umino and Sacks (1993) also found a departure from the constant $b$-value below about $\mathrm{M}=2.5$ to 3.5 even though the catalogues are complete above about $\mathrm{M}=2$. A decrease in the $b$-value for small earthquakes could be due to a breakdown at such events in the constant stress drop scaling relationship which governs larger earthquakes (Hanks 1979; Aki 1987; Rundle 1993). Archuleta et al. (1982) and others observed an apparent decrease in stress drop below about $\mathrm{M}=3$, with smaller events tending to a minimum source dimension of about $100 \mathrm{~m}$. These observations were controversial, as such a change in scaling could also be interpreted as resulting from severe attenuation beneath the recording site (Hanks 1982). From the source parameters for earthquakes determined from the seismograms recorded at $2.5 \mathrm{~km}$ depth in granite, in the Cajon Pass borehole, southern California, Abercrombie and Leary (1993) and Abercrombie (1995) found no breakdown in constant stress drop scaling in the range $0 \leq \mathrm{M} \leq 7$. They also observed source dimensions ten times smaller than the proposed "minimum". By comparing surface and downhole recordings of the same events, they stated that the apparent breakdown in scaling is simply an artifact of the limited spatial resolution of surface stations. Combining the results of high-gain microearthquake surveys with recorded seismicity by surface network along three active faults in California, Abercrombie and Brune (1994) obtained a constant $b=1$ for earthquakes with $M \geq 0$. Abercrombie (1996) stated that the decrease in $b$-value for small events is not just due to incompleteness of earthquake catalogue, but that small events are really not as numerous as a constant $b$-value extrapolated from moderate and larger earthquakes would predict.

On the right-hand side of the FM distribution, the pattern often changes from small/moderate to large earthquakes, with a break magnitude $\mathrm{M}_{2}$ as shown in line 1 of Fig. 2. The $M_{2}$ values measured by Pacheco et al. (1992) vary from 5.9 - 7.5 for various areas. For example, considering worldwide earthquakes listed in Abe's (1981) catalogue the $b$-value changes at $\mathrm{M}_{2}=7.5$ from $1.04 \pm 0.03$ for small/ moderate earthquakes to $1.51 \pm 0.08$ for large ones. The two $b$-values are quite different. Pacheco et al. (1992) argued that $\mathrm{M}_{2}$ corresponds to the finite depth of seismogenic zone. Thus, small/moderate earthquakes could scale differently from large ones. Rydelek and Sacks (1989) and Ward (1998) assumed that such a change is attributed to a deficit in data recorded within a short time period. The deficit of large earthquakes would lead to an effect on reliability of seismic hazard assessment. Kisslinger (1992) asked a question: how exactly are the seismologists to compensate for this problem in seismic hazard assessment? In order to resolve these problems, some seismologists took non-GR laws to interpret the observations (for examples, Utsu 1974; Purcaru 1975; Lomnitz-Adler and Lomnitz 1978, 1979; Main 1992; Raschke 2015).

However, based on a complete data set for earthquakes in southern California Knopoff (2000) stressed that such a change does not exist and thus the GR law is valid in a large range of magnitudes as displayed by line 2 in Fig. 2. According to the self-organization spinodal model proposed by Rundle et al. (2000), the FM distributions can be classified into three types (as displayed in Fig. 2) associated with three time terms during an earthquake cycle. The three types of FM distributions contain almost all observations.

Okal and Romanowicz (1994) considered that the change in $b$-value is due to the saturation of moment-magnitude relationship caused by source finiteness. When a single magnitude scale is used, a $b$-value of unity can be expected only in a smaller range of earthquake size because the relevant magnitude is saturated for the event with size larger than the upper bound value. They argued that the widely expected $b=1$ should be from the practice of using a heterogeneous magnitude scale, e.g., $\mathbf{M}_{\mathrm{s}}$ for large events and $\mathrm{m}_{\mathrm{b}}$ for smaller ones.

Indeed, a number of factors can influence the $b$-value. For a review of these factors see Frohlich and Davis (1993). According to geological survey data and laboratory results, Scholz (1968) stressed the importance of the rock type, stress, and confining pressure on the $b$-value. Ductile rock has a higher $b$-value than brittle rock. King (1983) correlated the $b$-value to self-similar geological structures. From laboratory experiments on precursory microcracking in stressed rock samples, Main et al. (1989) considered two types of models from the stress-time behavior: the first model for elastic failure (time-predictable model) and the second one for anelastic failure (involving precursory strain energy release). Their new model can explain the major temporal fluctuations in $b$-value in terms of the underlying physical processes of time-varying applied stress and crack growth under a constant strain rate. The model predicts two minima in the $b$-value, separated by a temporary maximum inflexion point; a corollary being that a single broad maximum would be expected in scattering attenuation. These fluctuations in $b$-value are consistent with reported 'intermediate-term' and 'short-term' earthquake precursors separated by a period of 
seismic quiescence. From the analyses of small scale fracture processes expressed by acoustic emissions (AEs) through Xray computer tomography $(\mathrm{CT})$ scans of faulted rock samples with spatial maps of $b$-values, Goebel et al. (2012) found that the geometric asperities identified in CT scan images were connected to regions of low $b$-values, increased event densities and moment release over multiple stick-slip cycles. Their experiments underline several parallels between laboratory findings and studies of crustal seismicity, for example, that asperity regions in the lab and field are connected to spatial $b$-value anomalies. These regions appear to play an important role in controlling the nucleation spots of dynamic slip events and crustal earthquakes. Goebel et al. $(2012,2013)$ investigated variations in seismic $b$-values for $\mathrm{AE}$ events during the stress buildup and release on laboratory-created fault zones. They showed that $b$-values mirror periodic stress changes that occur during a series of stick-slip events, and are correlated with stress over many seismic cycles. Moreover, the amount of $b$-value increase associated with slip events indicates the extent of the corresponding stress drop. Hence, they concluded that $b$-value variations can be used to approximate the stress state on a fault: a possible tool for the advancement of time-dependent seismic hazard assessment.

From the observations of $b$-value related to coda-Q, Aki (1985) and Patanè et al. (1992) observed the correlation between the two parameters and suggested that higher structural heterogeneity leads to larger $b$-value. However, Wang et al. (1989) observed that the coda-Q did not change prior to the 1986 Hualien, Taiwan, earthquake, but it abruptly reduced after the event. Hence, the correlation between the parameters was low before the earthquake. Main et al. (1992) pointed out that lower stress intensity and/or greater material heterogeneity produces higher $b$-value.

The spatial distribution $b$-value is considered to be highly correlated to tectonics by numerous authors (e.g., Miyamura 1962; Wang 1988; Tsapanos 1990; Khan et al. 2011). Wang (1988) observed that a stronger hydrothermal activity, especially in the volcanic area, can yield a higher $b$-value. Schorlemmer et al. (2005) addressed that the $b$ value varies systematically for different styles of faulting. They observed that normal faulting events have the highest $b$-values, thrust events the lowest, and strike-slip events intermediate values. Given that thrust faults tend to be under higher stress than normal faults they inferred that the $b$-value acts as a stress meter that depends inversely on differential stress. However, their results are different from Wang's (1988). From a comparison between the spatial distribution of $b$-values in Wang (1988) and spatial distribution of stress field inferred from both focal mechanisms of earthquakes and micro-tectonic analyses of rocks as shown in Wang et al. (1994), we could not find a positive correlation between the $b$-values and focal mechanisms as well as stress field.

Numerous researchers theoretically studied the physics of the GR law based on different models. Bak et al. (1987,
1988) suggested a sandpile (or cellular automaton) model for the interpretation of power-law phenomena. This model shows the important property of self-organized criticality (SOC): from any initial state, the system evolves into a critical state characterized by a power-law distribution of activities. Based on the SOC concept, a model mathematically equivalent to the lattice model in the limit of zero-mass of the blocks has also been widely used by numerous authors in studying the FM relation. The statistical physics models, including the percolation theory, and numerical simulations based on a 3-D quasi-static elastic model have also been used to simulate the FM relation. A description concerning those models can be seen in Turcotte (1992) and Main (1996).

Burridge and Knopoff (1967) proposed a 1-D dynamical lattice model (abbreviated as the 1-D BK model hereafter) to approach fault dynamics. This model has since been applied to dynamically simulate earthquake occurrences and then simulation results were applied to interpret the GR's FM law of earthquakes (Otsuka 1972; Yamashita 1976; Rundle and Jackson 1977; Cao and Aki 1984, 1986; Carlson and Langer 1989; Carlson 1991; Carlson et al. 1991; Wang 1991, 1994a, 1995, 1996, 1997; Knopoff et al. 1992; Shaw et al. 1992; Shaw 1994, 1995; Schmittbuhl et al. 1996). A detailed review about the model and its applications can be seen in Wang (2008).

Burridge and Knopoff (1967) mentioned that the system exhibits the GR law, with $\mathrm{b} \approx 1$. Rundle and Jackson (1977) showed that the linear behavior of the FM relation is not an immutable law but is dependent on the mechanical properties of a fault. Carlson and Langer (1989) divided the simulation events into three types as shown in Fig. 3: microscopic, localized, and de-localized events. Only the localized events in the magnitude range from $M_{1}$ to $M_{2}$ show

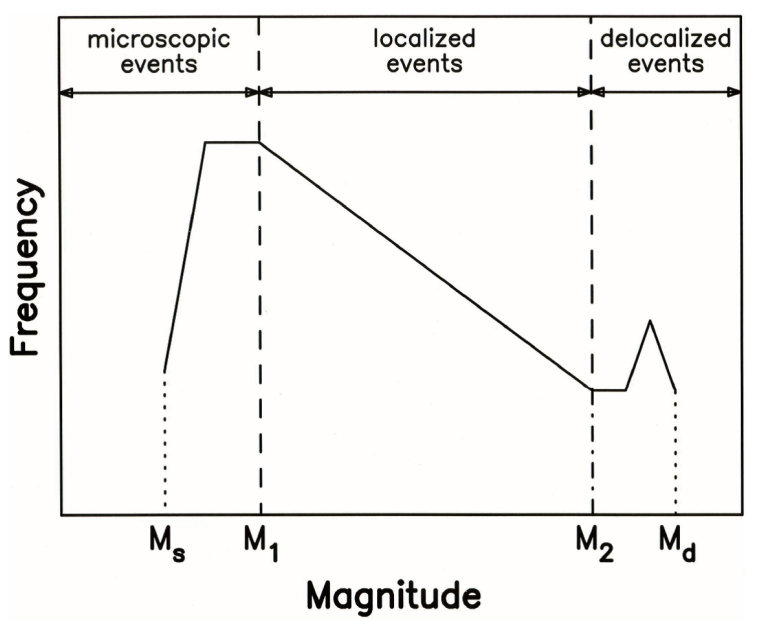

Fig. 3. The general pattern of the FM relationship: $M_{s}=$ the smallest event, $\mathrm{M}_{1}=$ the lower bound for the GR's FM law, $\mathrm{M}_{2}=$ the lower bound for the GR's FM law, and $\mathrm{M}_{\mathrm{d}}=$ the largest event. The microscopic, localized, and delocalized events are defined, respectively, for $\mathrm{M}<\mathrm{M}_{1}, \mathrm{M}_{1} \leq \mathrm{M} \leq \mathrm{M}_{2}$, and $\mathrm{M}>\mathrm{M}_{2}$ by Carlson and Langer (1989). 
a power-law function. Carlson and her co-workers (Carlson and Langer 1989; Carlson et al. 1991) stated that the magnitude range, i.e., the range from $M_{1}$ to $M_{2}$ in Fig. 3, of localized events is essentially influenced by several factors including the speed of the moving plate, the stiffness ratio, $s$, which is the ratio of the spring constant between two sliders over that between the moving plate and a slider, and the amount of the initial change in the frictional force from static to dynamic. Knopoff et al. (1992) stated that the GR law is a correlate of the geometry of localization.

Friction can affect the FM distribution and thus the $b$-value (e.g., Carlson and Langer 1989; Shaw 1994, 1995; Schmittbuhl et al. 1996; Wang 1996). Carlson and Langer (1989) stressed that the $b$-value is affected by a parameter $\alpha$, which is the ratio of the largest characteristic slipping speed to the speed at which the friction strength is appreciably reduced. The $b$-value first increases with $\alpha$ and then becomes a constant when $\alpha$ is larger than a certain value. Wang (1995) studied the effects on the GR's FM law due to the friction drop ratio, $\mathrm{g}$, and the maximum value of the breaking strength, $\mathrm{F}_{\text {oamx }}$. His results show that the $b$-value is larger for smaller $\mathrm{g}$ (a large friction drop) than for larger $\mathrm{g}$ (a small friction drop) and only weakly dependent upon $F_{\text {oamx }}$. Wang (1996) observed that the weakening rate, $r$, of the dynamic frictional force with sliding velocity remarkably affects the FM relation and the $b$-value decreases with increasing $r$. Large $r$ is more capable of localizing the events and prohibiting the generation of de-localized events than small $\mathrm{r}$ and the $b$-values are different for the three types of friction: the largest $b$-value for supersonic friction, the intermediate one for sonic friction, and the smallest one for subsonic friction. Shaw $(1994,1995)$ stressed that slip complexity due to slip-weakening friction can also produce the GR's FM law. Schmittbuhl et al. (1996) stated that for friction laws allowing local reversal backslipping, the FM distribution does not exhibit a GR's FM law.

When a slider stops moving after sliding, the healing of dynamic friction to static friction, including the type and delay time of healing, would influence the next rupture. In other words, non-instantaneous healing must be significant for seismicity (Rundle and Jackson 1977). Wang (1997) showed that the healing effect obviously affects the seismicity pattern, yet only has a small effect on the GR law.

Wang (1994a, 1995) stressed that the $b$-value of the cumulative FM relation is less than that of the discrete FM relation. This is similar to the result observed by Main (1992). Wang (1995) found that there is a power-law correlation between $\mathrm{b}$ and $\mathrm{s}: \mathrm{b} \sim \mathrm{s}^{-2 / 3}$ for the cumulative frequency and $\mathrm{b} \sim \mathrm{s}^{-1 / 2}$ for the discrete frequency. Lower fault stiffness results in a higher $b$-value. Wang and Huang (2001) found that a higher degree of non-uniform friction strengths leads to a higher $b$-value.

There is a question: can we predict the maximum earthquake, i.e., $\mathrm{M}_{\mathrm{d}}$ as shown in Fig. 3 , in a certain area from $\log \mathrm{N}=\mathrm{a}-\mathrm{bM}$, obtained from the earthquakes that occurred in the area over a certain time period, just by letting $\log \mathrm{N}=0$ ? The answer is not definite. There are two models that describe the problem (Wesnousky et al. 1983, 1984; Shimazaki 1986; Kagan 1993, 1996). The first is the $b$-value model, from which the answer is positive. The second is the $\mathrm{M}_{\max }$ model, from which the answer is negative. Experience shows that the former works when the data are incomplete and the latter is valid when the data are complete. Carlson's (1991) theoretical results exhibit the existence of the de-localized event with a magnitude of $\mathrm{M}_{\mathrm{d}}$, that depends strongly on the total rupture or fault length, as shown in Fig. 3. Such a de-localized event cannot be predicted from the GR law for localized events. Noted that the generation of de-localized events in her study is due mainly to a uniform distribution of frictional strengths. Simulations based on a non-uniform distribution of frictional strengths cannot result in de-localized events (Wang 1991, 1994a, 1995, 1996, 1997).

Self-similarity or scale-invariance is a universal property of natural phenomena. Mandelbrot (1982) proposed the fractal geometry concept with fractal dimension, D, to describe the scale-invariant natural phenomena. This concept has been widely applied to describing the spatial distribution and temporal variation in earthquakes and fault activities (cf. Scholz and Aviles 1986; Aviles et al. 1987; Turcotte 1989, 1992; Wang and Lee 1995, 1996).

Aki (1981) first postulated a positive relation between the $b$-value and the $\mathrm{D}$ value in the form $\mathrm{D}=3 \mathrm{~b} / \mathrm{c}$, where $\mathrm{c}$ is the slope of the log moment versus the magnitude relation, and thus $\mathrm{c}$ is about 1.5. The theoretical relation between the two parameters is $b=D / 3$ according to Turcotte (1986a) and $\mathrm{b}=\mathrm{D} / 2$ according to Turcotte (1986b) based on different models. Hirata (1989) reported a negative correlation between the two parameters for earthquakes in Japan. He also argued that the fractal dimension of the geometry of fault planes used by Aki is a special case of the capacity dimension of either an asperity or a barrier distribution in which all asperities or barriers are connected to each other without isolation, and where the dimension can be regarded as the fractal dimension of the surface of the fault plane. Yet, this is not necessarily true for the observed seismicity produced from various fault planes.

Omori (1894) first found that the number of aftershocks, $\mathrm{n}(\mathrm{t})$, decays with time in the following form: $\mathrm{n}(\mathrm{t})=\mathrm{k} / \mathrm{t}^{\mathrm{p}}$, where $\mathrm{k}$ and $\mathrm{p}$ are, respectively, the coefficient and the scaling exponent. This is the first scaling law of seismology and called the Omori law. The Omori law and the GR law are two basic scaling laws for earthquakes, and thus it is necessary to compare the scaling exponents of the two laws.

\section{EARTHQUAKE MONITORING IN TAIWAN}

Before 1896, only the historical documents reporting earthquake-induced damage were available (cf. Hsu 1983a, 
b). In 1897 when the Japanese occupied Taiwan, routine seismological service was started at Taihoku (Taipei) Meteorological Observatory. A history on the construction of seismic network in the Japanese period can be found in Hsu (1961, 1966) and Shin and Chang (2005). A simple history is described below. From 1897 - 1901 seismographs were installed at Keelung, Taipei, Taichung, Tainan, Penghu, and Hengchun. Later, the Wiechert seismographs were installed at Taipei in 1928, at Tainan, Hualien, and Alishan in 1933, at Taitung and Hengchung in 1934, and at Taichung in 1935. The Japanese seismologists constructed 17 stations in total in Taiwan, each equipped with three-component, low-gain displacement seismometers. The old-fashioned accelerometers were also installed at some stations. The seismograms for all stations were recorded in the analog form. The clocks at the stations were not synchronous, because the technicians at the local stations individually timed the clocks. This is the main shortcoming of the network. There were remarkable errors for the arrival times, thus resulting in high uncertainty in earthquake location (Chan and Wang 1990). At the end of the Second World War, this seismic network was transferred to the Taiwan Weather Bureau (TWB, now the CWB). A detailed description of the seismographs and operation of the network can be seen in Lee $(1983,1985)$. Since 1953 an earthquake bulletin including the phases and arrival times has been published (four volumes annually) first by the TWB and then by the CWB. The magnitude scale used in this period was Hsu's magnitude, i.e., $\mathrm{M}_{\mathrm{H}}$, which is comparable with $\mathrm{M}_{\mathrm{s}}$ (Wang 1992).

During the 1973 - 1992 period, the TTSN was operated by the Institute of Earth Sciences, Academia Sinica (ASIES). This network consisted of 24 stations, each equipped with a vertical, high-gain and analog velocity seismometer. A detailed description of this network can be seen in Wang (1989a). An earthquake catalogue including four volumes per year was published by the ASIES. The magnitude scale used in this period was the duration magnitude, $M_{D}$ (Wang 1992).

Since 1991 a new seismic network, named as the Taiwan Seismic Network (TSN) operated by the CWB, has been upgraded from the old CWB seismic network. Many new stations were constructed. In 1992 the TTSN was merged into the TSN. A detailed description about the TSN can be seen in Shin (1992) and Shin and Change (2005). At present, the TSN is composed of 72 stations, each equipped with three-component, digital velocity seismometers. These seismograms are recorded in both high- and low-gain forms. This network provides high-quality digital earthquake data to seismological communities. The magnitude scale used by the TSN is the simulated local magnitude, $\mathrm{M}_{\mathrm{L}}$, proposed by Shin (1993).

\section{OBSERVATIONS OF $\boldsymbol{b}$-VALUES IN TAIWAN}

\subsection{Spatial Distributions of $b$-Values}

Hsu (1971) first calculated the $b$-values for the whole
Taiwan region and three seismic zones: Western Seismic Zone (WSZ), Eastern Seismic Zone (ESZ), and Ryutai Seismic Zone (RSZ) from earthquake data with $\mathrm{M}_{\mathrm{H}} \geq 4$ recorded by the old CWB seismic network. His calculated $b$-values are 0.82 for the WSZ, 0.89 for the ESZ, 0.95 for the RSZ, and 0.95 for the whole region. The number of earthquakes used for estimating the $b$-value is 155 for the WSZ, 286 for the ESZ, 1124 for the RSZ and 1624 for the whole region. The number of events used for the last two is much larger than those for the first two. Hence, the similarity in the $b$ values for the latter two is obvious. For the $\mathrm{M}_{\mathrm{H}} \geq 5$ earthquakes occurring during the $1954-1968$ period, Lin (1970) measured the $b$-values for the four sub-regions of Taiwan from earthquake data recorded by the old CWB seismic network. His $b$-values vary from $0.4-0.9$.

After the construction of TTSN, Tsai et al. (1993b) measured the $b$-values for Taiwan from two data sets: one for earthquakes with $2.0 \leq \mathrm{M}_{\mathrm{D}} \leq 5.4$ occurring from 1 April to 30 June 1973 and the other for the pre-1972 earthquakes with $4.0 \leq \mathrm{M}_{\mathrm{H}} \leq 7.6$. The $b$-values are almost 1 for the two data sets. Tsai et al. (1981) estimated the $b$-values for Taiwan and its three seismic zones from $M_{D} \geq 3$ earthquakes occurred between 1973 and 1979. In the western zone, where only shallow earthquakes were located, the $b$-values are 1.19 for its northern part and 1.18 for its southern part. The $b$-value is 1.14 for the eastern zone, which has a great majority of shallow events with a small fraction of intermediate-depth events. In the northeastern zone, where both shallow and intermediate-depth events were located, the $b$-values are 1.12 for shallow earthquakes and 0.97 for deep events. Obviously, the $b$-value is depth-dependent for the northern zone.

Chen and Wang (1985) divided the Taiwan region into several ten $20^{\prime} \times 20^{\prime}$ units, and then calculated the $b$-values for $M_{D} \geq 1$ earthquakes with depths less than $40 \mathrm{~km}$ occurring during the 1973 - 1985 period. Wang (1988) plotted the equal-b contours of the region (see Fig. 4) using the results obtained by Chen and Wang (1985), with some revisions, and also interpreted the results. The $b$-value map is shown in Fig. 4. The average $b$-value is about 1.1 and the equal-b contour of this value is almost along the eastern coastal line of Taiwan. The average $b$-value is similar to those obtained by Tsai et al. (1981). Wang's results show that the $b$-value is in general smaller offshore than on land. On land, the $b$ value decreases from east to west. Small $b$-values appear at the leading edge of the subducting slab of the Philippine Sea plate. A large $b$-value appears in northern Taiwan including the TVG. This implies the existence of geothermal activity under the area. This is consistent with the high heat flux in the area (Lee and Cheng 1986).

Wang (1988) related the equal-b contours to regional tectonics and geology. The $b$-value contours are oriented in a NNE-SSW direction. Generally speaking, the $b$-values are smaller offshore than on land. To the west of the Longitudinal Valley in eastern Taiwan, with a few exceptions, a 
positive correlation exists between the $b$-value distribution and the geotectonic map. In addition to the similar orientation, the $b$-values are corrected with the degree of metamorphism of rocks. Both decrease in the same trend from the east to the west. Around the leading edge, where the Wadati- Benioff zone of the Philippine Sea plate begins its subduction, the small $b$-values may reflect high stress due to bending in the oceanic plate. Large $b$-values are found in the Tatun and Chilungshan volcano groups and cover a wider area than the surface distribution of igneous rocks. In central Taiwan, the low Bouguer gravity anomalies coincide with small $b$ values. Offshore in eastern Taiwan, over the transition from the continental crust on the west side to the oceanic crust on the east side, the small $b$-values are accompanied by large Bouguer gravity anomalies with a large gradient of about $4 \mathrm{mgal} \mathrm{km}^{-1}$. The spatial distribution of $b$-values will be significant for understanding the geotectonics.

Cheng and Yeh (1989) compiled a catalogue from several catalogues for Taiwan's earthquakes during 1604 1988. The magnitude scale is the local magnitude proposed by Yeh and Hsu (1985). They transformed the magnitude scale from $M_{H}$ to $M_{L}$ for earthquakes before 1972 through the $\mathrm{M}_{\mathrm{L}}-\mathrm{M}_{\mathrm{H}}$ conversion formula inferred by them and from $M_{D}$ to $M_{L}$ for those since 1972 through the $M_{L}-M_{D}$ conversion formula inferred by Yeh and Hsu (1985). Noted that the local magnitude, $\mathrm{M}_{\mathrm{L}}$, defined by Yeh and Hsu (1985) is different from that defined by Shin (1993). Based on the new catalogue with $\mathrm{M}_{\mathrm{L}}$, they estimated the $b$-values for Taiwan for three time periods: $b=1.06\left(6 \leq \mathrm{M}_{\mathrm{L}} \leq 8\right)$ for the 1898 - 1935 period, $b=1.17\left(6 \leq M_{L} \leq 7\right)$ for the $1936-1972$ period, and $b=1.12\left(4.0 \leq \mathrm{M}_{\mathrm{L}} \leq 6.5\right)$ for the $1973-1988$ period. Essentially, it is insignificant to compare the three $b$-values, because they did not examine the completeness of the three data sets. The number of smaller-sized earthquakes for the first period is much smaller than those for the last two. Meanwhile, the magnitude scales for the first two periods are different from that for the third period. However, their $b$-value for the third period is similar to that measured by Wang (1988) and Tsai et al. (1993b).

Based on the CWB's catalogue with $\mathrm{M}_{\mathrm{L}}$ for Taiwan earthquakes located by the TSN, Shin and Chang (1992) calculated the $b$-value for earthquakes $\left(2.8 \leq \mathrm{M}_{\mathrm{L}} \leq 5.4\right)$ in 1992 and their value is 0.99. Chang and Shin (1994) calculated the $b$-value for the earthquakes $\left(3.2 \leq \mathrm{M}_{\mathrm{L}} \leq 5.6\right)$ in 1993 and their value is 1.08 . Although the two $b$-values are slightly different, we cannot exactly distinguish them because the authors did not provid the standard errors.

Kim et al. (2005) calculated the $b$-value for shallow earthquakes with $2.0 \leq \mathrm{M}_{\mathrm{D}} \leq 5.4$. The earthquake data were taken from the TTSN for the time period from $1973-1990$ and from the TSN since 1991. Their $b$-value is 0.94, which is smaller from those calculated by Tsai et al. $(1983,1993 b)$ and Wang (1988), but similar to that by Hsu (1971). Kim et al. (2005) calculated the $b$-value after the 1999 Chi-Chi earthquake. That earthquake caused many larger-sized aftershocks. This would increase the weighting of moderate and large events on the calculation of $b$-value, thus leading to a smaller $b$-value.

Wu et al. (2013) evaluated the GR's FM relationship for Taiwan's earthquakes reported by the CWB since 1900. A break in the FM distribution for large earthquakes is observed. The $b$-value is about 1 when $\mathrm{M}<7$ and 1.5 when $\mathrm{M} \geq 7$. If the GR scaling for $\mathrm{M}<7$ earthquakes is extrapolated to larger earthquakes, an $M>8$ earthquake is expected in the region about every $25 \mathrm{yr}$. However, their analysis shows a lower frequency of occurrence for large earthquakes so that the expected frequency for $M>8$ earthquakes is about $200 \mathrm{yr}$. They claimed that the level of seismicity for smaller earthquakes in Taiwan is about 12 times higher than that in Southern California and the possibility for the occurrence of an $\mathrm{M} \approx 9$ earthquake in north or south Taiwan cannot be ruled out.

Several authors calculated the $b$-values from local seismicity. Yeh (1973) calculated the $b$-value (=1.38) of the Juisui area from a micro-earthquake survey after the 24 April 1972 Jui-sui earthquake. Wang and Chin (1984) calculated the $b$-value of microseismicity with $\mathrm{M}_{\mathrm{D}} \geq 0.9$ in the middle part of the Taitung Longitudinal Valley and its vicinity from a seismic survey. They divided the area into five zones. The calculated $b$-values are 1.46, 1.08, 1.83, 1.33, and 1.29 for zones $1,2,3,4$, and 5 , respectively. They also correlated the $b$-values with local geology and geothermal activities. From the $\mathrm{M} \geq 4$ earthquakes that occurred during the $1973-1988$ period recorded by the TTSN, Wang (1989b) measured the

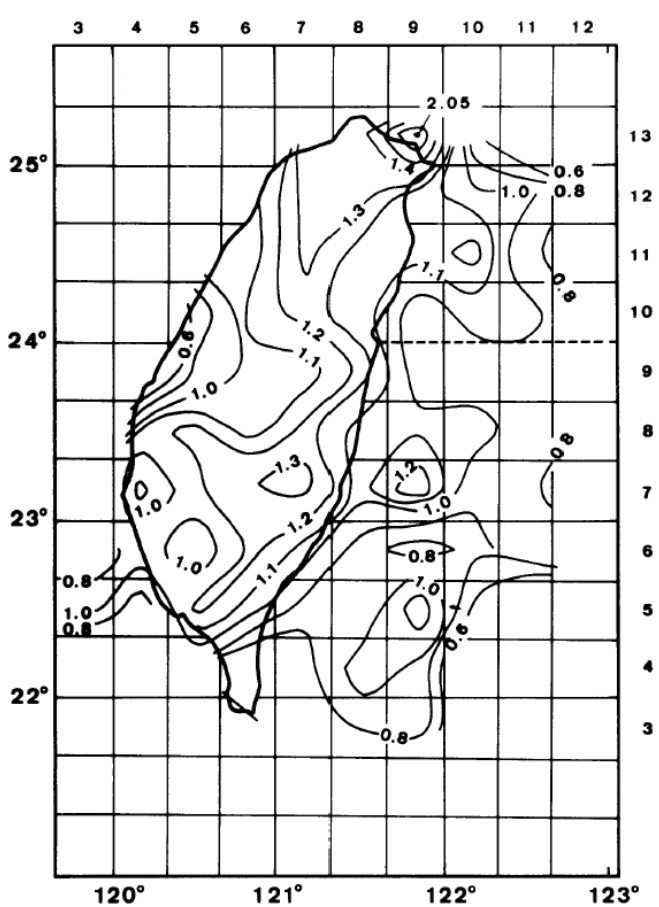

Fig. 4. The constant $b$-value contours in the Taiwan region (after Wang 1988). 
$b$-values for four zones in the southernmost part of Okinawa. The $b$-values vary from $0.71-1.44$ for various zones, and the value is 0.97 for the whole area. Wang et al. (1990) measured the $b$-value $(=1.23)$ for earthquakes occurred in the Juisui area during the 1973 - 1987 period from earthquake data recorded by the TTSN. Their value is smaller than that calculated by Yeh (1973). Ou (1996) measured the $b$-value in the Chiayi-Tainan area from earthquake data recorded by the seismic network of a local seismic array operated by the Institute of Seismology, National Chung-Cheng University.

Wang (1988) observed a higher $b$-value around the TVG in northern Taiwan than in others. From shallow earthquakes occurred in the TVG during 1973 - 1999, Kim et al. (2005) estimated $b=1.22 \pm 0.05$ for the magnitude range $2.1-3.5$. They also stated that the earthquake data in the study area should be completed when $\mathrm{M}>2$. Wang et al. (1994) observed that except for the earthquakes in the subduction zone, the events occurring in northern Taiwan are usually shallow. Kim et al. (2005) also obtained similar results for $\mathrm{M}>2$ events. They also found that three $\mathrm{M} \geq 2.8$ events occurring below the TVG show normal faulting. Tsai et al. (1993a) observed that most of earthquakes occurring in the TVG show normal faulting. Chen and Yeh (1991) observed that most of micro-earthquakes $\left(0.2 \leq \mathrm{M}_{\mathrm{D}}<3.0\right)$ in the TVG were located at depths shallower than $10 \mathrm{~km}$ and show normal faulting. Lin et al. (2005) stressed that earthquakes occurring underneath the TVG are located mainly at a depth range of $2-4 \mathrm{~km}$. From the depth profile of micro-earthquakes with $\mathrm{M}_{\mathrm{L}}<2.8$, Konstantinou et al. (2007) observed that all events have a focal depth less than $6 \mathrm{~km}$. Hence, in the area, high $b$-values $(=1.17)$, shallow focal depths, and normal faulting might all show strong geothermal activities with high temperatures caused by past volcanic activities. Based on the concept proposed by Scholz (1990), these studies also imply that the seismogenic zone below the TVG is thinner than other zones.

The problem of depth dependence of FM distributions (cf. Mori and Abercrombie 1997) is also significant for understanding the seismogenic-zone structures, tectonics, and seismic hazard assessment. As mentioned above, Tsai et al. (1993b) first observed different $b$-values for earthquakes of different focal depths in northern Taiwan: 1.12 for shallow earthquakes and 0.97 for deep events. Chen and Yeh (2014) calculated the $b$-values from earthquakes that occurred from 1991 - 2014 in the Yun-Chia-Nan area, southwestern Taiwan and constructed a 3-D structure of $b$-values. The calculated $b$-values vary from $0.6-1.2$. The $b$-value is clearly depth-dependent and low $b$-values appear in the depth range 5 - $15 \mathrm{~km}$. Lower $b$-values appear below the Chi-Yi City and Chung-Pu Township.

Previous studies show that the average $b$-value for the entire Taiwan region is around 1.0, but it is also slightly dependent upon the earthquake data in use, including the study area, time period, focal depth, and magnitude scale. Local $b$-values vary area to area and time to time. Earthquake data recorded over a long time period is necessary in order to obtain a stable $b$-value in an area.

Wang (1983) used the double exponential function, which is not a GR law: $\ln (\mathrm{N})=\mathrm{a}^{\prime}-\mathrm{c}^{\prime} \exp \left(\mathrm{b}^{\prime} \mathrm{M}\right)$, where a', b', and c' are three constants that describe the FM distribution of $\mathrm{M} \geq 3.5$ earthquakes from 1935 - 1983 in Taiwan. Although the model fit to the observations is not too bad, he claimed that the double exponential FM relation is less useful than the GR law.

\section{$4.2 b$-Values for Individual Earthquakes}

The $b$-values were also estimated for foreshocks and/or aftershocks from some larger-sized earthquakes by several authors. Lee and Tsai (1981) calculated the $b$-value of aftershocks ( $\left.3.0 \leq M_{D} \leq 5.4\right)$ for the 23 July $1978 M_{D} 6.0$ Lanhsu, Taiwan, earthquake from the TTSN data. Their $b$-value is 1.04. Chen and Wang (1984) calculated the $b$-values of background seismicity (before May 6), foreshocks (May 6 to May 10), and aftershocks (after May 10) of the 10 May $1983 \mathrm{M}_{\mathrm{D}}$ 5.7 Taipingshan, Taiwan, earthquake from the TTSN data. Their $b$-values for $2 \leq \mathrm{M}_{\mathrm{D}} \leq 4$ are $1.13 \pm 0.02$ for background seismicity, $0.99 \pm 0.08$ for foreshocks, and $1.20 \pm 0.06$ for aftershocks. After the March 1991 Chia-li, southwest Taiwan, earthquake sequence, Shin et al. (1994) observed that the $b$-value for earthquakes in the source area is about 0.93 from earthquake data recorded by the TSN. Chen et al. (1996) calculated the $b$-value for aftershocks of the 16 September $1994 \mathrm{M}_{\mathrm{s}} 7.3$ southern Taiwan Strait earthquake. Their $b$-value is 0.9 for $3.0 \leq \mathrm{M}_{\mathrm{L}} \leq 5.5$. This is the first $b$-value for the Taiwan Strait.

Tsai et al. (2006) applied the dense-gridding technique proposed by Wiemer and Katsumata (1999) to study the spatial distributions and temporal variations of $b$-values in the source region of the 1999 Chi-Chi, Taiwan, earthquake. They considered three regions over the north, central and south parts (i.e., regions A, B, and, C, respectively) of the Chelungpu fault (see Fig. 4a in their article). Their technique uses overlapping grids centered at nodes $5 \mathrm{~km}$ apart with $20 \mathrm{~km}$ in radius. Tsai et al.'s (2006) primary objective was to find areas where the $b$-value significantly changed before the ChiChi earthquake. In one grid there are $\mathrm{n}_{1}$ and $\mathrm{n}_{2}$ earthquakes, respectively, with magnitudes $\mathrm{M}_{1 \mathrm{i}}\left(\mathrm{i}=1,2,3, \ldots \mathrm{n}_{1}\right)$ for 1994 - 1995 and $\mathrm{M}_{2 \mathrm{i}}\left(\mathrm{i}=1,2,3, \ldots \mathrm{n}_{2}\right)$ for 1997. The average magnitudes are $\mathrm{M}_{1}$ and $\mathrm{M}_{2}$, and the corresponding $b$-values are $\mathrm{b}_{1}$ and $\mathrm{b}_{2}$. The standardized $b$-value change is defined by a $\mathrm{Z}$-value, which is the estimated variance of $b_{i}(i=1,2)$, proposed by Shi and Bolt (1982). Therefore, a grid is claimed to have an anomalous change, at an approximate significance level of 0.10 , if $|Z|>1.282$. The spatial distributions of $Z$ values obtained by Tsai et al. (2006) suggest a significant increase in $b$-value to the west of the northern Chelungpu fault together with a significant decrease in $b$-value to the 
east of the central Chelungpu fault just north of the epicenter. Moreover, in region $\mathrm{C}$, the increase and decrease in $b$-values were significant in the southwest and east, respectively, of the Ruey-Li epicenter. Again, such a seismicity anomaly indicates a possible precursor of the Ruey-Li earthquake.

\subsection{Temporal Variations in $b$-Value}

Chen et al. (1990) studied premonitory phenomena prior to the $\mathrm{M}_{\mathrm{D}}$ 5.7 Taipingshan, Ilan, Taiwan, earthquake of 10 May 1983. Before the mainshock, a low seismicity zone appeared in the source area, where foreshocks and aftershocks were located. The epicentral pattern of aftershocks showed a significant correlation with an unexposed fault zone. The monthly frequency of events displayed abnormal seismicity both in the source area and its neighborhood. This abnormal seismicity migrated somewhat from the outside area into the source area. About one and a half years before the mainshock, the $b$-values, especially in the source area, increased markedly but then decreased about one year before the mainshock. However, in the surrounding area the $b$-values did not change too much. In other words, their results showed areadependence in abnormal $b$-value as mentioned above.

Chen (2003) plotted the FM distributions of earthquakes that occurred in Taiwan preceding the 1999 ChiChi earthquake. The FM distributions were made for three terms: (a) the earlier term from 1991 - 1993, (b) the midterm from 1994 - 1997, and (c) the precursory term from 1998 1999. The FM distributions in the three time terms are like those from lines 1 - 3 as shown in Fig. 2. For the earlier term, the distribution changes at the crossover magnitude, $\mathrm{M}_{\mathrm{c}}=5$, from small/moderate earthquakes to large events. $\mathbf{M}_{\mathrm{c}}$ is just $\mathrm{M}_{2}$ as displayed in Figs. 1 - 3. The distribution can be described using the GR law when $\mathrm{M}<\mathrm{M}_{\mathrm{c}}$, and there is a fall-off in the cumulative frequency when $M>M_{c}$. In the midterm, the fall-off almost disappears. The FM distribution, like line 1 in Fig. 2, was found for earthquakes that occurred from 1991 - 1993, and that like line 2 was observed for the earthquakes from 1994. The earthquakes happened in the precursory term (after 1998 and before the Chi-Chi mainshock) exhibited a higher activity of moderate-size events with $\mathrm{M}>5$. However, he did not calculate $b$-values for the three terms.

Tsai et al. (2006) investigated the possible precursory changes in seismicity preceding the Chi-Chi earthquake. They calculated the $b$-value of three regions (regions A, B, and $\mathrm{C}$ from north to south) in the source area. Based on complete recordings of $\mathrm{M}_{\mathrm{L}} \geq 2.0$ earthquakes within $40 \mathrm{~km}$ in depth, they examined the temporal variations in $b$-values from 1 January 1994 to 31 August 1999 in each region. The $b$-values were computed using a 100 -event window sliding by 10 events. Their results show that the highest $b$-value in region A appeared in early 1997, and the $b$-value in region $\mathrm{B}$ reached its peak in late 1997 . The $b$-values in the two re- gions obviously increased about two years prior to the mainshock, and thus such anomalies could be a possible precursor of the mainshock. Although there were relatively high $b$-values in region C during 1997 , the $b$-value dramatically decreased to 0.65 after the $\mathrm{M}_{\mathrm{L}} 6.2$ Ruey-Li earthquake of 1 July 1998 . Hence, the $b$-value anomaly in region C might be contaminated by aftershocks of the Ruey-Li earthquake.

Wu et al. (2008) plotted the FM distributions of earthquakes that occurred in southern Taiwan preceding the Pingtung doublets $\left(\mathrm{M}_{\mathrm{L}}=6.7\right.$ and 6.4) of 26 December 2006 . They found the data set is complete when $\mathrm{M}_{\mathrm{L}}>3.2$. The events occurred from March 2004 about three years before the Pingtung doublets were taken into account. The FM distributions were made for the whole time period in use and three intervals: the first from 1 January 2000 to 15 March 2002; the second one from 15 March 2002 to 1 March 2004; and the third one from 1 March 2004 to 25 December 2006. The FM distributions in the three time intervals are like those shown in Fig. 2. From the FM distributions, they observed a deficit in moderate events with magnitude $5 \sim 6$ before March 2002 and a gradual increase in the number of moderate events from March 2002 to March 2004. After March 2004 and before the Pingtung doublets the number of moderate events increased further, indicating the precursory activation of moderate earthquakes in the study area. However, they did not calculate the $b$-values .

Lin (2010) obtained the temporal variations in $b$-values for the 4 March $2008 \mathrm{M}_{\mathrm{L}} 5.2$ Taoyuan earthquake in southern Taiwan. There were two groups of foreshocks (64 events), clustered along the narrow major fault zone, and several hundred aftershocks. A high $b$-value of $\sim 1.25$ calculated from the foreshocks was significantly larger than those from aftershocks $(b=0.80)$ and background seismicity $(b=0.81)$. About one month before the earthquake sequence, some micro-earthquakes, with an extremely high $b$-value of $\sim 2.1$, appeared. He assumed that this anomaly indicated pre-nucleation seismic features near the fault zone.

Chan et al. (2012) investigated the spatial and temporal variations in $b$-values before twenty-three earthquakes with $\mathrm{M}_{\mathrm{L}} \geq 6$ in Taiwan from $1999-2009$. They estimated the spatial distribution of $b$-values in five years with a unit of one year before respective mainshocks. Results exhibit that the epicenter of each earthquake in the study was located predominately in an area with low $b$-values. The $b$-values were slightly lower during the year prior to the target earthquakes than those in the periods two to five years earlier. They proposed that such anomalies might offer spatiotemporal constraints for earthquake forecasting. Nevertheless, from the five-year time variations (with a unit in one year) in average $b$-values for twenty-three earthquakes (see Fig. 5 of their paper) we can see that the highest average $b$-value appeared in the fourth time period from one year to two years prior to the forthcoming earthquakes. Although the average $b$-value in the fourth time period is only slightly higher than those in 
the first three time periods, the results still suggest the appearance of slightly higher $b$-values one year prior to forthcoming earthquakes.

Previous studies show that abnormally high $b$-values appeared in general about one year or more years prior to the mainshock. The occurrence time for the $b$-value anomaly is on average shorter forearthquakes in Taiwan than those in New Zealand.

\subsection{Correlation Between $b$-Value and Fractal Dimension}

A fractal set is defined as one for which the HausdorffBesicovitch (HB) dimension strictly exceeds the commonlyused topological dimension (Mandelbrot 1982). The fractal dimension is a characteristic index of a fractal set. However, it is not easy to practically apply the HB dimension to estimate the fractal dimension. Several alternatives have been suggested (cf. Takayasu 1990). Similarity dimension $D_{S}$ is defined for an exactly self-similar set as $D_{S}=\log (L) /$ $\log (\mathrm{N})$, where $\mathrm{L}$ is the linear size and $\mathrm{N}$ is the number of the similar daughters. Capacity dimension $\mathrm{D}_{\mathrm{CA}}$ is defined as $\mathrm{D}_{\mathrm{CA}}=\log [\mathrm{N}(\mathrm{r})] / \log (1 / \mathrm{r})$, where $\mathrm{N}(\mathrm{r})$ is the smallest number of covering of a set with a size of $r$. Information dimension $D_{I}$ is defined as $D_{I}=\sum p_{i}(r) \log \left[p_{i}(r)\right] / \log (r)$, where $r$ is the distance between two points, based on the probabilistic distribution $\mathrm{p}_{\mathrm{i}}(\mathrm{r})$, which will be described below. Correlation dimension $\mathrm{D}_{\mathrm{C}}$ is defined from the correlation integral $\mathrm{C}(\mathrm{r})$ in the following relation: $\mathrm{C}(\mathrm{r}) \sim \mathrm{r}^{\mathrm{Dc}-\mathrm{d}}$, where $\mathrm{d}$ is the spatial (or topological) dimension (2 and 3 for the 2D and $3 \mathrm{D}$ spaces) and $\mathrm{C}(\mathrm{r})$ is defined for the epicentral distribution $\left\{\mathrm{r}_{\mathrm{i}}\right\}(\mathrm{i}=1,2,3, \ldots, \mathrm{N})$ as $\mathrm{C}(\mathrm{r})=2 \mathrm{~N}(\mathrm{R}<\mathrm{r}) / \mathrm{N}(\mathrm{N}-1)$, where $\mathrm{N}(\mathrm{R}<\mathrm{r})$ is the number of pairs of events with a distance $\mathrm{R}<\mathrm{r}$ (cf. Grassberger and Procaccia 1983). In general, $D_{S}=D_{C A} \geq D_{I} \geq D_{C}$, and $D_{C}$ is the smallest value of the four fractal dimensions. The equality $D_{S}=D_{C A}=D_{I}=D_{C}$ holds only in the case of a homogeneous fractal set. Most natural fractals are not completely self-similar and actually multifractal. For such fractals, $D_{S}=D_{C A}>D_{I}>D_{C}$. Hence, a single fractal dimension is not sufficient to characterize the multifractal properties. Therefore, Grassberger (1983) and Hentschel and Procaccia (1983) suggested the idea of generalized fractal or multi-fractal dimension, $\mathrm{D}_{\mathrm{q}}$. Wang and Lee (1995) proposed that a $D_{q}-q$ relation rather than the first three values of $\mathrm{D}_{\mathrm{q}}$ can completely represent the multifractal behavior of a time series.

As mentioned above, a positive relation between the $b$-value and the $\mathrm{D}$ value was postulated in the following forms: $\mathrm{D}=3 \mathrm{~b} / \mathrm{c}(\mathrm{c}=1.5)$ by Aki $(1981) ; \mathrm{b}=\mathrm{D} / 3$ by Turcotte (1986a); and $b=D / 2$ by Turcotte (1986b). However, Hirata (1989) reported a negative correlation between the two parameters for earthquakes in Japan. He also argued the possible problem given by Aki as mentioned above.

Wang (1991) studied the correlation between the $b$ - value and the fractal dimension of the distribution of the breaking strengths from synthetic seismicity based on the 1-D BK model. His simulations exhibit weak dependence of the $b$-value upon the $\mathrm{D}$ value. This conclusion is different from the theoretical postulation made by Aki (1981) and Turcotte (1986a, b) and from the observations (Hirata 1989). A possible reason for the difference might be that the D used by Wang (1991) concerns the distribution of the breaking strengths on a fault while the D used by the others is related to the fault geometry.

Wang and Lin (1993) measured the (correlation) fractal dimensions, $\mathrm{D}_{\mathrm{c}}$, of epicentral distributions of earthquakes of two zones, separated by the latitude of $24^{\circ} \mathrm{N}$, in western Taiwan. Results show that $D_{c}=1.3$ for the north zone is less than $D_{c}=1.6$ for the south zone. This indicates that the distribution of northern events is less dense than that of southern ones. From Fig. 4, we can see that the average $b$-value is higher in north zone than in the south zone. The $\mathrm{D}$ value is negatively correlated with the $b$-value as pointed out by Hirata (1989). Wang and Lee (1996) measured the generalized fractal dimension for the epicentral distribution of earthquakes in western Taiwan. They divided the whole area into two zones, i.e., north and south zones, and then they further separated the two zones into three sub-zones for the former and two for the latter. They also constructed the $\mathrm{D}_{\mathrm{q}} \mathrm{-q}$ relations for $\mathrm{q}=0,1,2, \ldots, 15$ for the two zones and five sub-zones. Results show significant multifractal behavior and spatial variation in multifractality for epicentral distributions of earthquakes in western Taiwan, and the $\mathrm{D}$ value is negatively correlated with the $b$-value as pointed out by Hirata (1989).

\subsection{Correlation Between $b$-Value and p-Value}

Omori (1894) first proposed a power law to describe the variation in the number of aftershocks with time: $\mathrm{n}(\mathrm{t})=\mathrm{k} / \mathrm{t}^{\mathrm{p}}$. This power law is called the Omori law, which is the first scaling law in seismology. Several studies were done to interpret the physics of $b$ and p-values. Mogi (1967) found that the regions where aftershocks decrease rapidly with larger p-values are specified with high heat flow and then suggested that the residual stress at the aftershock region relaxes fast in the high-temperature state due to rock flow. He also related the power law to the mechanism that the stress rapidly decreases immediately after the mainshock and gradually approaches a constant value. Scholz (1968) suggested that aftershocks are produced by creep rupture due to stress corrosion in the regions of stress concentration following the mainshock. Yamashita and Knopoff (1987) considered two models to interpret aftershock activity: (1) aftershocks are assumed to be caused by subsequent slip on asperities of a fault that lock during the fracture in the mainshock; and (2) aftershocks are caused by catastrophic coalescence of nearby small fractures with the fracture surface 
of the mainshock. Subcritical stress corrosion cracking is usually assumed to be the main fracture mechanism for the two cases. Considering aftershocks to be decayed responses to stress changes induced by the mainshock, Chen et al. (2012) assumed that the mechanical Maxwell or Kelvin element must play a role in aftershock generation and simulated aftershocks based on the 1-D BK model. Their simulation results reveal the existence of aftershocks specified with the Omori law with $\mathrm{p} \approx 0.8$ and changes in the stiffness or strength of materials control aftershock generation.

Since the $b$ - and p-values represent the states of fracture and the stresses of the source area, the correlation between them must show significant constraint for the construction of a model to interpret aftershock activity. Under the consideration of seismic energy decay with time in the form of the power law, Utsu (1961) concluded that the $b$-value is positively correlated with the p-value. He also plotted the data points of $b$ versus $p$-values for Japanese earthquakes. However, the data points in his article somewhat form a cluster, and the correlation was not studied; hence, his conclusion is questionable. Through dynamical modeling, Burridge and Knopoff (1967) postulated that the cumulative energy released in aftershocks since the onset of the sequence is in the exponential function. From the aforementioned models, Yamashita and Knopoff (1987) theoretically derived a positive correlation between $b$ - and p-values, especially for the late-occurring aftershocks. However, for nine large Chinese earthquakes Ma et al. (1990) suggested a negative correlation between the two parameters. Wang (1994b) observed a negative correlation between the two parameters from a larger set of observed data of $b$ - and p-values for tens of worldwide earthquakes. Nevertheless, the data points of $b$ versus $p$ in Wang (1994b) are scattering due to uncertainties of evaluating the $b$ - and p-values, especially for the former. It is necessary to collect more data to examine the correlation in advance. Unfortunately, the origin of the relation between $\mathrm{p}$ - and $b$-values is still unknown.

\section{SUMMARY}

High seismicity with spatial heterogeneity in Taiwan makes the region one of the best natural laboratories for seismological studies. Hence, seismicity studies, including the $b$-value, have been performed in Taiwan for more than a century. One of the possible ways to mitigate seismic risk is predicting an impending earthquake through the observations of seismic precursors. The research on seismic precursors started almost in 1978. Since then, several projects of seismic precursors have been conducted by different agencies. This review study focuses on the studies of $b$-values of earthquakes in Taiwan, including spatial distribution of $b$ values, temporal variation in $b$-values, correlation between $b$ value and fractal dimension, and correlation between $b$ - and p-value of Omori's law for aftershocks. Also included is the relation between spatial distribution of $b$-values and regional geotectonics. Intrinsic properties and theories of $b$-value and earthquake monitoring in Taiwan are also briefly described.

Several conclusions can be made and are described below. The average $b$-value for the entire Taiwan region is around 1.0 , but it is also slightly dependent upon the earthquake data in use, including the time period and magnitude scale. Local $b$-values are of time-, area-, and depth-dependent. In order to obtain a stable $b$-value in an area, the earthquake data recorded over a long time period is necessary. The spatial distribution of $b$-values is strongly related to regional geotectonics. Abnormally high $b$-values appeared in general about one more years prior to the mainshock for Taiwan's earthquakes. The fractal dimension of earthquakes is negatively proportional to the $b$-value. The p-value of aftershocks is negatively proportional to the $b$-value.

Acknowledgements This study was financially supported by Academia Sinica, Ministry of Science and Technology (Grand No.: MOST 103-2116-M-001-010), and the Central Weather Bureau (Grand No.: MOTC-CWB-104-E-07).

\section{REFERENCES}

Abe, K., 1981: Magnitudes of large shallow earthquakes from 1904 to 1980. Phys. Earth Planet. Inter., 27, $72-$ 92, doi: 10.1016/0031-9201(81)90088-1. [Link]

Abercrombie, R. E., 1995: Earthquake source scaling relationships from -1 to $5 M_{L}$ using seismograms recorded at 2.5-km depth. J. Geophys. Res., 100, 24015-24036, doi: 10.1029/95JB02397. [Link]

Abercrombie, R. E., 1996: The magnitude-frequency distribution of earthquakes recorded with deep seismometers at Cajon Pass, southern California. Tectonophysics, 261, 1-7, doi: 10.1016/0040-1951(96)00052-2. [Link]

Abercrombie, R. E. and J. N. Brune, 1994: Evidence for a constant $b$-value above magnitude 0 in the southern San Andreas, San Jacinto and San Miguel fault zones, and at the Long Valley Caldera, California. Geophys. Res. Lett., 21, 1647-1650, doi: 10.1029/94GL01138. [Link]

Abercrombie, R. E. and P. Leary, 1993: Source parameters of small earthquakes recorded at $2.5 \mathrm{~km}$ depth, Cajon Pass, southern California: Implications for earthquake scaling. Geophys. Res. Lett., 20, 1511-1514, doi: 10.1029/93GL00367. [Link]

Aki, K., 1965: Maximum likelihood estimate of $b$ in the formula $\log \mathrm{N}=\mathrm{a}-\mathrm{bM}$ and its confidence limits. Bull. Earthq. Res. Inst., 43, 237-239.

Aki, K., 1981: A probabilistic synthesis of precursory phenomena. In: Simpson, D. W. and P. G. Richards (Eds.), Earthquake Prediction, American Geophysical Union, Washington, D. C., USA, 566-574, doi: 10.1029/ ME004p0566. [Link] 
Aki, K., 1985: Theory of earthquake prediction with special reference to monitoring of the quality factor of lithosphere by the coda method. In: Kisslinger, C. and T. Rikitake (Eds.), Practical Approaches to Earthquake Prediction and Warning, Springer Netherlands, 219230, doi: 10.1007/978-94-017-2738-9_2. [Link]

Aki, K., 1987: Magnitude-frequency relation for small earthquakes: A clue to the origin of $f_{\max }$ of large earthquakes. J. Geophys. Res., 92, 1349-1355, doi: 10.1029/ JB092iB02p01349. [Link]

Aki, K., 1995: Earthquake prediction, societal implications. Rev. Geophys., 33, 243-247, doi: 10.1029/95RG00396. [Link]

Archuleta, R. J., E. Cranswick, C. Mueller, and P. Spudich, 1982: Source parameters of the 1980 Mammoth Lakes, California, earthquake sequence. J. Geophys. Res., 87, 4595-4607, doi: 10.1029/JB087iB06p04595. [Link]

Aviles, C. A., C. H. Scholz, and J. Boatwright, 1987: Fractal analysis applied to characteristic segments of the San Andreas fault. J. Geophys. Res., 92, 331-344, doi: 10.1029/JB092iB01p00331. [Link]

Bak, P., C. Tang, and K. Wiesenfeld, 1987: Self-organized criticality: An explanation of the 1/f noise. Phys. Rev. Lett., 59, 381-384, doi: 10.1103/PhysRevLett.59.381. [Link]

Bak, P., C. Tang, and K. Wiesenfeld, 1988: Self-organized criticality. Phys. Rev. A, 38, 364-374, doi: 10.1103/ PhysRevA.38.364. [Link]

Burridge, R. and L. Knopoff, 1967: Model and theoretical seismicity. Bull. Seismol. Soc. Am., 57, 341-371.

Cao, T. and K. Aki, 1984: Seismicity simulation with a mass-spring model and a displacement hardening-softening friction law. Pure Appl. Geophys., 122, 10-24, doi: 10.1007/BF00879646. [Link]

Cao, T. and K. Aki, 1986: Seismicity simulation with a rateand state-dependent friction law. Pure Appl. Geophys., 124, 487-513, doi: 10.1007/BF00877213. [Link]

Carlson, J. M., 1991: Time intervals between characteristic earthquakes and correlations with smaller events: an analysis based on a mechanical model of a fault. J. Geophys. Res., 96, 4255-4267, doi: 10.1029/90JB02474. [Link]

Carlson, J. M. and J. S. Langer, 1989: Mechanical model of an earthquake fault. Phys. Rev. A, 40, 6470-6484, doi: 10.1103/PhysRevA.40.6470. [Link]

Carlson, J. M., J. S. Langer, B. E. Shaw, and C. Tang, 1991: Intrinsic properties of a Burridge-Knopoff model of an earthquake fault. Phys. Rev. A, 44, 884-897, doi: 10.1103/PhysRevA.44.884. [Link]

Chan, C. H., Y. M. Wu, T. L. Tseng, T. L. Lin, and C. C. Chen, 2012: Spatial and temporal evolution of $b$-values before large earthquakes in Taiwan. Tectonophysics, 532-535, 215-222, doi: 10.1016/j.tecto.2012.02.004. [Link]
Chan, C. W. and J. H. Wang, 1990: The error range and $\mathrm{P}$-wave residual to the relocation of earthquakes in the Juisui area during January 1969 to May 1972 by HYPO71 program. Meteorol. Bull. CWB, 36, 305-314. (in Chinese)

Chang, J. S. and T. C. Shin, 1994: Earthquakes in 1993. Meteorol. Bull. CWB, 39, 202-217. (in Chinese)

Chen, C. C., 2003: Accelerating seismicity of moderate-size earthquakes before the 1999 Chi-Chi, Taiwan, earthquake: Testing time-prediction of the self-organizing spinodal model of earthquakes. Geophys. J. Int., 155, F1-F5, doi: 10.1046/j.1365-246X.2003.02071.x. [Link]

Chen, C. C., J. H. Wang, and W. J. Huang, 2012: Material decoupling as a mechanism of aftershock generation. Tectonophysics, 546-547, 56-59, doi: 10.1016/j. tecto.2012.04.016. [Link]

Chen, C. H. and Y. L. Yeh, 2014: Earthquake potential in the Yun-Chia area, SW Taiwan: Insight from b-value. Proc. 2014 Seminar on Earthquake Monitoring and Earthquake Precursors, Central Weather Bureau.

Chen, K. C. and J. H. Wang, 1984: On the studies of the May 10, 1983 Taipingshan, Taiwan earthquake sequence. Bull. Inst. Earth Sci. Acad. Sin., 4, 1-27.

Chen, K. C. and J. H. Wang, 1985: The b-value distribution and seismicity maps of the Taiwan region. Proc. ROCJAPAN Seminar on Multiple Hazards Mitigation, Nation Taiwan University, Taipei, Taiwan, ROC, 69-82.

Chen, K. C., J. H. Wang, and Y. L. Yeh, 1990: Premonitory phenomena of a moderate Taiwan earthquake. Terr. Atmos. Ocean. Sci., 1, 1-21.

Chen, K. J. and Y. H. Yeh, 1991: Gravity and microearthquake studies in the Chinshan-Tanshui area, northern Taiwan. Terr. Atmos. Ocean. Sci., 2, 35-50.

Chen, T., D. Jiang, N. Chen, Z. Lo, W. Han, H. Zhang, and D. Xi, 1984a: Characteristics of seismic activity of the Songpan-Pingwu earthquakes. Earthquake Prediction, Terra Scientific Publishing Company, Tokyo, Unesco, Paris, 79-89.

Chen, X., D. Yuan, and C. Wu, 1996: Characteristics of source ruptures of $\mathrm{M}_{\mathrm{s}} 7.3$ southern Taiwan Strait earthquake and analysis of seismicity in coastal area in southeastern China. Acta Seism. Sinica, 18, 145-155. (in Chinese)

Chen, Y. T., Z. L. Chen, and B. Q. Wang, 1992: Seismological studies of earthquake prediction in China: A review. In: Dragoni, M. and E. Boschi (Eds.), Earthquake Prediction, Roma: Il Cigno Galileo Galilei, 71-109.

Chen, Z., P. Liu, D. Huang, D. Zheng, F. Xue, and Z. Wang, 1984b: Characteristics of regional seismicity before major earthquakes. Earthquake Prediction, Terra Scientific Publishing Company, Tokyo, Unesco, Paris, 505-521.

Cheng, S. N. and Y. T. Yeh, 1989: Catalogue of Earthquakes in Taiwan from 1604 to 1988, Open-File Rept., 
Inst. Earth Sci., Acad. Sin., 255 pp. (in Chinese)

DasGupta, S., B. Mukhopadhyay, and A. Bhattacharya, 2007: Seismicity pattern in north Sumatra-Great Nicobar region: In search of precursor for the 26 December 2004 earthquake. J. Earth Syst. Sci., 116, 215-223, doi: 10.1007/s 12040-007-0021-7. [Link]

DasGupta, S., B. Mukhopadhyay, and M. Mukhopadhyay, 2012: Earthquake forerunner as probable precursor An example from North Burma subduction zone. $J$. Geol. Soc. India, 80, 393-402, doi: 10.1007/s12594012-0157-1. [Link]

Eguchi, T. and S. Uyeda, 1983: Seismotectonics of the Okinawa trough and Ryukyu arc. Mem. Geol. Soc. China, 5, 189-210.

Ekström, G. and A. M. Dziewonski, 1988: Evidence of bias in estimations of earthquake size. Nature, 332, 319323, doi: 10.1038/332319a0. [Link]

Fiedler, G., 1974: Local $b$-values related to seismicity. Tectonophysics, 23, 277-282, doi: 10.1016/00401951(74)90027-4. [Link]

Frohlich, C. and S. D. Davis, 1993: Teleseismic $b$ values; or, much ado about 1.0. J. Geophys. Res., 98, 631-644, doi: 10.1029/92JB01891. [Link]

Geller, R. J., 1997: Earthquake prediction: A critical review. Geophys. J. Int., 131, 425-450, doi: 10.1111/j.1365246X.1997.tb06588.x. [Link]

Geller, R. J., D. D. Jackson, Y. Y. Kagan, and F. Mulargia, 1997: Earthquakes cannot be predicted. Science, 275, 1616-1617, doi: 10.1126/science.275.5306.1616. [Link]

Goebel, T. H. W., T. W. Becker, D. Schorlemmer, S. Stanchits, C. Sammis, E. Rybacki, and G. Dresen, 2012: Identifying fault heterogeneity through mapping spatial anomalies in acoustic emission statistics. J. Geophys. Res., 117, B03310, doi: 10.1029/2011JB008763. [Link]

Goebel, T. H. W., D. Schorlemmer, T. W. Becker, G. Dresen, and C. G. Sammis, 2013: Acoustic emissions document stress changes over many seismic cycles in stickslip experiments. Geophys. Res. Lett., 40, 2049-2054, doi: 10.1002/grl.50507. [Link]

Grassberger,P., 1983: Generalized dimensions of strange attractors. Phys. Lett. A, 97, 227-230, doi: 10.1016/03759601(83)90753-3. [Link]

Grassberger, P. and I. Procaccia, 1983: Measuring the strangeness of strange attractors. Phys. Nonlinear Phenom., 9, 189-208, doi: 10.1016/0167-2789(83)90298-1. [Link]

Gutenberg, B. and C. F. Richter, 1944: Frequency of earthquakes in California. Bull. Seismol. Soc. Am., 34, 185-188.

Hanks, T. C., 1979: $b$ values and $\omega^{-\gamma}$ seismic source models: Implications for tectonic stress variations along active crustal fault zones and the estimation of high-frequen- cy strong ground motion. J. Geophys. Res., 84, 22352242, doi: 10.1029/JB084iB05p02235. [Link]

Hanks, T. C., 1982: $f_{\max }$. Bull. Seismol. Soc. Am., 72, 1867-1879

Hentschel, H. G. E. and I. Procaccia, 1983: The infinite number of generalized dimensions of fractals and strange attractors. Phys. Nonlinear Phenom., 8, 435-444, doi: 10.1016/0167-2789(83)90235-X. [Link]

Hirata, T., 1989: A correlation between the $b$ value and the fractal dimension of earthquakes. J. Geophys. Res., 94, 7507-7514, doi: 10.1029/JB094iB06p07507. [Link]

Ho, C. S., 1975: An Introduction to the Geology of Taiwan Explanatory Text of the Geologic Map of Taiwan, the Ministry of Economic Affairs, Republic of China, $271 \mathrm{pp}$.

Holub, K., 1996: Space-time variations of the frequencyenergy relation for mining-induced seismicity in the Ostrava-Karviná mining district. Pure Appl. Geophys., 146, 265-280, doi: 10.1007/BF00876493. [Link]

Hsu, H., 1983a: Source materials on the history of natural disasters in Ching Taiwan. Hazards Mitigation S\&T Report, Vol. 72-01, 5-6. (in Chinese).

Hsu, M. T., 1961: 29. Seismicity of Taiwan (Formosa). Bull. Earthq. Res. Inst., 39, 831-847.

Hsu, M. T., 1966: Seismicity of Taiwan. Meteorol. Bull. $C W B, 12,33-51$. (in Chinese)

Hsu, M. T., 1971: Seismicity of Taiwan and some related problems. Bull. Intern. Inst. Seismol. Earthq. Eng., Tokyo, 8, 41-160.

Hsu, M. T., 1983b: Estimation of earthquake magnitudes and seismic intensities of destructive earthquakes in the Ming and Ching Eras. Meteorol. Bull. CWB, 29, 1-18. (in Chinese)

Kagan, Y. Y., 1993: Statistics of characteristic earthquakes. Bull. Seismol. Soc. Am., 83, 7-24.

Kagan, Y. Y., 1996: Comment on "The Gutenberg-Richter or characteristic earthquake distribution, which is it?" by Steven G. Wesnousky. Bull. Seismol. Soc. Am., 86, 274-285.

Khan, P. K., M. Ghosh, P. P. Chakraborty, and D. Mukherjee, 2011: Seismic $b$-value and the assessment of ambient stress in Northeast India. Pure Appl. Geophys., 168, 1693-1706, doi: 10.1007/s00024-010-0194-x. [Link]

Kiek, S. N., 1984: Earthquake prediction from $b$-values. $N a$ ture, 310, 456, doi: 10.1038/310456b0 . [Link]

Kim, K. H., C. H. Chang, K. F. Ma, J. M. Chiu, and K. C. Chen, 2005: Modern seismic observations in the Tatun volcano region of northern Taiwan: Seismic/volcanic hazard adjacent to the Taipei metropolitan area. Terr. Atmos. Ocean. Sci., 16, 579-594.

King, G., 1983: The accommodation of large strains in the upper lithosphere of the earth and other solids by selfsimilar fault systems: The geometrical origin of b-value. Pure Appl. Geophys., 121, 761-815, doi: 10.1007/ 
BF02590182. [Link]

Kisslinger, C., 1992: Sizing up the threat. Nature, 355, 1819, doi: 10.1038/355018a0. [Link]

Knopoff, L., 1996: Earthquake prediction: The scientific challenge. Proc. Natl. Acad.Sci. USA, 93, 3719-3720.

Knopoff, L., 2000: The magnitude distribution of declustered earthquakes in Southern California. Proc. Natl. Acad.Sci. USA, 97, 11880-11884.

Knopoff, L., Y. Y. Kagan, and R. Knopoff, 1982: $b$ values for foreshocks and aftershocks in real and simulated earthquake sequences. Bull. Seismol. Soc. Am., 72, 1663-1676.

Knopoff, L., J. A. Landoni, and M. S. Abinante, 1992: Dynamical model of an earthquake fault with localization. Phys. Rev. A, 46, 7445-7449.

Konstantinou, K. I., C. H. Lin, and W. T. Liang, 2007: Seismicity characteristics of a potentially active Quaternary volcano: The Tatun Volcano Group, northern Taiwan. J. Volcanol. Geotherm. Res., 160, 300-318, doi: 10.1016/j.jvolgeores.2006.09.009. [Link]

Lahaie, F. and J. R. Grasso, 1999: Loading rate impact on fracturing pattern: Lessons from hydrocarbon recovery, Lacq Gas Field, France. J. Geophys. Res., 104, 17941-17954, doi: 10.1029/1999JB900139. [Link]

Lee, C. R. and W. T. Cheng, 1986: Preliminary heat flow measurements in Taiwan. Fourth Circum-Pacific Energy and Mineral Resources Conference, Singapore.

Lee, P. H., 1983: The strong earthquake records of 1900 to 1972: Re-analysis and occurrence time, spatial distributions study in Taiwan area. Rept. Central Weather Bureau, 49 pp. (in Chinese)

Lee, P.H., 1985: The seismic network of the Central Weather Bureau. Proc. Seminar Commem. 50th Anniv. for Hsinchu-Taichung Earthquake of 1935, 114-123. (in Chinese)

Lee, T. Q. and Y. B. Tsai, 1981: A study of the July 23, 1978 Lanhsu, Taiwan earthquake sequence. Bull. Inst. Earth Sci. Acad. Sin., 1, 31-50.

Li, Q. L., J. B. Chen, L. Yu, and B. L. Hao, 1978: Time and space scanning of the b-value - A method for monitoring the development of catastrophic earthquakes. Chin. J. Geophys., 21, 101-125. (in Chinese)

Lin, C. H., 2002: Active continental subduction and crustal exhumation: The Taiwan orogeny. Terra Nova, 14, 281-287.

Lin, C. H., 2010: Temporal $b$-value variations throughout a seismic faulting process: The 2008 Taoyuan earthquake in Taiwan. Terr. Atmos. Ocean. Sci., 21, 229234, doi: 10.3319/TAO.2009.02.09.01(T). [Link]

Lin, C. H., K. I. Konstantinou, W. T. Liang, H. C. Pu, Y. M. Lin, S. H. You, and Y. P. Huang, 2005: Preliminary analysis of volcanoseismic signals recorded at the Tatun Volcano Group, northern Taiwan. Geophys. Res. Lett., 32, L10313, doi: 10.1029/2005GL022861. [Link]
Lin, J. H., 1970: Statistical analysis of earthquake occurrence in Taiwan 1954-1968. Bull. Inst. Geophys., 8, 45-55.

Lomnitz-Adler, J. and C. Lomnitz, 1978: A new magnitudefrequency relation. Tectonophysics, 49, 237-245, doi: 10.1016/0040-1951(78)90184-1. [Link]

Lomnitz-Adler, J. and C. Lomnitz, 1979: A modified form of the Gutenberg-Richter magnitude-frequency relation. Bull. Seismol. Soc. Am., 69, 1209-1214.

Ma, Z., Z. Fu, Y. Zhang, C. Wang, G. Zangh, and D. Liu, 1990: Earthquake Prediction: Nine Major Earthquakes in China (1966-1976), Springer-Verlag Berlin Heidelberg, New York, 332 pp.

Main, I., 1992: Earthquake scaling. Nature, 357, 27-28, doi: 10.1038/357027a0. [Link]

Main, I., 1996: Statistical physics, seismogenesis, and seismic hazard. Rev. Geophys., 34, 433-462, doi: 10.1029/96RG02808. [Link]

Main, I. G., P. G. Meredith, and C. Jones, 1989: A reinterpretation of the precursory seismic $b$-value anomaly from fracture mechanics. Geophys. J.Int.,96, 131-138, doi: 10.1111/j.1365-246X.1989.tb05255.x. [Link]

Main, I. G., P. G. Meredith, and P. R. Sammonds, 1992: Temporal variations in seismic event rate and $b$-values from stress corrosion constitutive laws. Tectonophysics, 211, 233-246, doi: 10.1016/0040-1951(92)90061A. [Link]

Mandelbrot, B. B., 1982: The Fractal Geometry of Nature, W. H. Freeman and Company, San Francisco, CA, USA, $468 \mathrm{pp}$.

Miyamura, S., 1962: Magnitude-frequency relation of earthquakes and its bearing on geotectonics. Proc.Jpn. Acad., 38, 27-30.

Moatti, A., M. R. Amin-Nasseri, and H. Zafarani, 2013: Pattern recognition on seismic data for earthquake prediction purpose. Proceedings of the 2013 International Conference on Environment, Energy, Ecosystems and Development, 141-146.

Mogi, K., 1967: Regional variations in magnitude-frequency relation of earthquakes. Bull. Earthq. Res. Inst., 45, 313-325.

Mori, J. and R. E. Abercrombie, 1997: Depth dependence of earthquake frequency-magnitude distributions in California: Implications for rupture initiation. J. Geophys. Res., 102, 15081-15090, doi: 10.1029/97JB01356. [Link]

Nanjo, K. Z., N. Hirata, K. Obara, and K. Kasahara, 2012: Decade-scale decrease in $b$ value prior to the M9-class 2011 Tohoku and 2004 Sumatra quakes. Geophys. Res. Lett., 39, L20304, doi: 10.1029/2012GL052997. [Link]

Okal, E. A. and B. A. Romanowicz, 1994: On the variation of $b$-values with earthquake size. Phys. Earth Planet. Inter., 87, 55-76, doi: 10.1016/0031-9201(94)90021-3. [Link]

Omori, F., 1894: Investigation of aftershocks. Rep. Earthq. 
Inv. Comm., 2, 103-139.

Otsuki, K. and T. Dilov, 2005: Evolution of hierarchical selfsimilar geometry of experimental fault zones: Implications for seismic nucleation and earthquake size.J.Geophys. Res., 110, B03303, doi: 10.1029/2004JB003359. [Link]

Otsuka, M., 1972: A simulation of earthquake occurrence. Phys. Earth Planet. Inter., 6, 311-315, doi: 10.1016/0031-9201(72)90015-5. [Link]

Ou, G. B., 1996: A study of seismicity in the Tainan-Chiayi area. Proc. 6th Taiwan Symp. Geophys., 57-66. (in Chinese)

Pacheco, J. F., C. H. Scholz, and L. R. Sykes, 1992: Changes in frequency-size relationship from small to large earthquakes. Nature, 355, 71-73, doi: 10.1038/355071a0. [Link]

Patanè, D., T. Caltabiano, E. Del Pezzo, and S. Gresta, 1992: Time variation of $b$ and $Q_{\mathrm{c}}$ at Mt. Etna (19811987). Phys. Earth Planet. Inter., 71, 137-140, doi: 10.1016/0031-9201(92)90070-C. [Link]

Purcaru, G., 1975: A new magnitude-frequency relation for earthquakes and a classification of relation types. Geophys.J.Int., 42, 61-79, doi: 10.1111/j.1365-246X.1975. tb05850.x. [Link]

Raschke, M., 2015: Modeling of magnitude distributions by the generalized truncated exponential distribution. $J$. Seismol., 19, 265-271, doi: 10.1007/s10950-014-94601. [Link]

Rikitake, T., 1975: Earthquake precursors. Bull. Seismol. Soc. Am., 65, 1133-1162.

Rikitake, T., 1987: Earthquake precursors in Japan: Precursor time and detectability. Tectonophysics, 136, 265282, doi: 10.1016/0040-1951(87)90029-1. [Link]

Rundle, J. B., 1993: Magnitude-frequency relations for earthquakes using a statistical mechanical approach. J. Geophys. Res., 98, 21943-21949, doi: 10.1029/93JB02037. [Link]

Rundle, J. B. and D. D. Jackson, 1977: Numerical simulation of earthquake sequences. Bull. Seismol. Soc. Am., 67, 1363-1377.

Rundle, J. B., W. Klein, D. L. Turcotte, and B. D. Malamud, 2000: Precursory seismic activation and critical-point phenomena. Pure Appl. Geophys., 157, 2165-2182, doi: 10.1007/PL00001079. [Link]

Rydelek, P. A. and I. S. Sacks, 1989: Testing the completeness of earthquake catalogues and the hypothesis of self-similarity. Nature, 337, 251-253, doi: 10.1038/337251a0. [Link]

Sammonds, P. and M. Ohnaka, 1998: Evolution of microseismicity during frictional sliding. Geophys. Res. Lett., 25, 699-702, doi: 10.1029/98GL00226. [Link]

Schmittbuhl, J., J. P. Vilotte, and S. Roux, 1996: A dissipation-based analysis of an earthquake fault model. J. Geophys. Res., 101, 27741-27764, doi:
10.1029/96JB02294. [Link]

Scholz, C. H., 1968: The frequency-magnitude relation of microfracturing in rock and its relation to earthquakes. Bull. Seismol. Soc. Am., 58, 399-415.

Scholz, C. H., 1990: The Mechanics of Earthquakes and Faulting, Cambridge University Press, Cambridge, New York, 439 pp.

Scholz, C. H. and C. A. Aviles, 1986: The fractal geometry of faults and faulting. In: Das, S., J. Boatwright, and C. H. Scholz (Eds.), Earthquake Source Mechanics, Geophysical Monograph Series, Vol. 37, American Geophysical Union, Washington, D.C., USA, 147-155.

Schorlemmer, D., S. Wiemer, and M. Wyss, 2005: Variations in earthquake-size distribution across different stress regimes. Nature, 437, 539-542, doi: 10.1038/ nature04094. [Link]

Schurr, B., G. Asch, S. Hainzl, J. Bedford, A. Hoechner, M. Palo, R. Wang, M. Moreno, M. Bartsch, Y. Zhang, O. Oncken, F. Tilmann, T. Dahm, P. Victor, S. Barrientos, and J. P. Vilotte, 2014: Gradual unlocking of plate boundary controlled initiation of the 2014 Iquique earthquake. Nature, 512, 299-302, doi: 10.1038/nature13681. [Link]

Shaw, B. E., 1994: Complexity in a spatially uniform continuum fault model. Geophys. Res. Lett., 21, 19831986, doi: 10.1029/94GL01685. [Link]

Shaw, B. E., 1995: Frictional weakening and slip complexity in earthquake faults. J. Geophys. Res., 100, 1823918251, doi: 10.1029/95JB01306. [Link]

Shaw, B. E., J. M. Carlson, and J. S. Langer, 1992: Patterns of seismic activity preceding large earthquakes. $J$. Geophys. Res., 97, 479-488, doi: 10.1029/91JB01796. [Link]

Shi, Y. and B. A. Bolt, 1982: The standard error of the magnitude-frequency $b$ value. Bull. Seismol. Soc. Am., 72, 1677-1687.

Shimazaki, K, 1986: Small and large earthquakes: The effects of the thickness of seismogenic layer and the free surface. In: Das, S., J. Boatwright, and C. H. Scholz (Eds.), Earthquake Source Mechanics, Geophysical Monograph Series, Vol. 37, American Geophysical Union, Washington, D.C., USA, 209-216.

Shin, T. C., 1992: Some implications of Taiwan tectonic features from the data collected by the Central Weather Bureau Seismic Network. Meteorol. Bull. CWB, 38, 23-48. (in Chinese)

Shin, T. C., 1993: The calculation of local magnitude from the simulated Wood-Anderson seismograms of the short-period seismograms in the Taiwan area. Terr. Atmos. Ocean. Sci., 4, 155-170.

Shin, T. C. and J. S. Chang, 1992: Earthquakes in 1992. Meteorol. Bull. CWB, 38, 218-232.

Shin, T. C. and J. S. Chang, 2005: Earthquake monitoring systems in Taiwan. In: Wang, J. H. (Ed.), The 921 
Chi-Chi Major Earthquake, Office of Inter-Ministry Science and Technology Program for Earthquake and Active-fault Research, NSC, 43-59. (in Chinese)

Shin, T.C., C. H. Chang, and C. H. Ching, 1994: The March 1991 Chia-li earthquake sequence. Meteorol. Bull. $C W B, 40,17-36$. (in Chinese)

Smith, W.D., 1981: The $b$-value as an earthquake precursor. Nature, 289, 136-139, doi: 10.1038/289136a0. [Link]

Smith, W. D., 1986: Evidence for precursory changes in the frequency-magnitude $b$-value. Geophys. J. R. astr. Soc., 86, 815-838, doi: 10.1111/j.1365-246X.1986. tb00662.x. [Link]

Suyehiro, S., 1966: Difference between aftershocks and foreshocks in the relationship of magnitude to frequency of occurrence for the great Chilean earthquake of 1960. Bull. Seismol. Soc. Am., 56, 185-200.

Takayasu, H., 1990: Fractals in the Physical Sciences, Nonlinear Science Series, Manchester University Press, Manchester, 170 pp.

Taylor, D. W. A., J. A. Snoke, I. S. Sacks, and T. Takanami, 1990: Nonlinear frequency-magnitude relationships for the Hokkaido corner, Japan. Bull. Seismol. Soc. Am., 80, 340-353.

Tsai, Y.B., 1986: Seismotectonics of Taiwan. Tectonophysics, 125, 17-37, doi: 10.1016/0040-1951(86)90005-3. [Link]

Tsai, Y. B., T. L. Teng, J. M. Chiu, and H. L. Liu, 1977: Tectonic implications of the seismicity in the Taiwan region. Mem. Geol. Soc. China, 2, 13-41.

Tsai, Y. B., Z. S. Liaw, T. Q. Lee, M. T. Lin, and Y. H. Yeh, 1981: Seismological evidence of an active plate boundary in the Taiwan area. Mem. Geol. Soc. China, 4, 143-154.

Tsai, Y. B., T. L. Teng, Y. H. Yeh, S. B. Yu, K. K. Liu, and J. H. Wang, 1983: Status of earthquake prediction research in Taiwan, ROC. Bull. Inst. Earth Sci. Acad. Sin., 3, 1-26.

Tsai, Y. B., H. B. Liaw, and C. C. Feng, 1993a: A study of microearthquakes in the Tatun volcanic region in northern Taiwan. Annual Report of the Institute of Physics, Academia Sinica, Taiwan, 239-250.

Tsai, Y. B., T. L. Teng, H. B. Liaw, and C. C. Feng, 1993b: New seismic data of Taiwan region. Annual Report of the Institute of Physics, Academia Sinica, Taiwan, 223-237.

Tsai, Y. B., J. Y. Liu, K. F. Ma, H. Y. Yen, K. S. Chen, Y. I. Chen, and C. P. Lee, 2006: Precursory phenomena associated with the 1999 Chi-Chi earthquake in Taiwan as identified under the iSTEP program. Phys. Chem. Earth, 31, 365-377, doi: 10.1016/j.pce.2006.02.035. [Link]

Tsapanos, T. M., 1990: $b$-values of two tectonic parts in the Circum-Pacific belt. Pure Appl. Geophys., 134, 229242, doi: 10.1007/BF00876999. [Link]
Turcotte, D. L., 1986a: Fractals and fragmentation. J. Geophys. Res., 91, 1921-1926, doi: 10.1029/ JB091iB02p01921. [Link]

Turcotte, D. L., 1986b: A fractal model for crustal deformation. Tectonophysics, 132, 261-269, doi: 10.1016/00401951(86)90036-3. [Link]

Turcotte, D. L., 1989: Fractals in geology and geophysics. Pure Appl. Geophys., 131, 171-196, doi: 10.1007/ BF00874486. [Link]

Turcotte, D. L., 1992: Fractals and Chaos in Geology and Geophysics, Cambridge University Press, New York, USA, $221 \mathrm{pp}$.

Umino, N. and I. S. Sacks, 1993: Magnitude-frequency relations for northeastern Japan. Bull. Seismol. Soc. Am., 83, 1492-1506.

Utsu, T., 1961: A statistical study on the occurrence of aftershocks. Geophys. Mag., 30, 521-605.

Utsu, T., 1974: A three-parameter formula for magnitude distribution of earthquakes. J. Phys. Earth, 22, 71-85, doi: 10.4294/jpe1952.22.71. [Link]

Wang, C. Y. and T. C. Shin, 1998: Illustrating 100 years of Taiwan seismicity. Terr. Atmos. Ocean. Sci., 9, 589-614.

Wang, J. H., 1983: Double exponential frequency-magnitude relationship of earthquakes occurred at Taiwan region. Bull. Inst. Earth Sci. Acad. Sin., 3, 27-36.

Wang, J. H., 1988: $b$ values of shallow earthquakes in Taiwan. Bull. Seismol. Soc. Am., 78, 1243-1254.

Wang, J. H., 1989a: The Taiwan Telemetered Seismographic Network. Phys. Earth Planet. Inter., 58, 9-18, doi: 10.1016/0031-9201(89)90090-3. [Link]

Wang, J. H., 1989b: Aspects of seismicity in the southernmost part of the Okinawa trough. Proc. Geol. Soc. China, 32, 79-99.

Wang, J. H., 1991: A note on the correlation between bvalue and fractal dimension from synthetic seismicity. Terr. Atmos. Ocean. Sci., 2, 317-329.

Wang, J. H., 1992: Magnitude scales and their relations for Taiwan earthquakes: A review. Terr. Atmos. Ocean. Sci., 3, 449-468.

Wang, J. H., 1994a: Scaling of synthetic seismicity from a one-dimensional dissipative, dynamic lattice model. Phys. Lett. A, 191, 398-402, doi: 10.1016/03759601(94)90793-5. [Link]

Wang, J. H., 1994b: On the correlation of observed Gutenberg-Richter's $b$ value and Omori's $p$ value for aftershocks. Bull. Seismol. Soc. Am., 84, 2008-2011.

Wang, J. H., 1995: Effect of seismic coupling on the scaling of seismicity. Geophys. J. Int., 121, 475-488, doi: 10.1111/j.1365-246X.1995.tb05727.x. [Link]

Wang, J. H., 1996: Velocity-weakening friction as a factor in controlling the frequency-magnitude relation of earthquakes. Bull. Seismol. Soc. Am., 86, 701-713.

Wang, J. H., 1997: Effect of frictional healing on the scaling 
of seismicity. Geophys. Res. Lett., 24, 2527-2530, doi: 10.1029/97GL02523. [Link]

Wang, J. H., 1998: Studies of earthquake seismology in Taiwan during the 1897-1996 period. J. Geol. Soc. China, 41, 291-336.

Wang, J. H., 2008: One-dimensional dynamical modeling of earthquakes: A review.Terr. Atmos. Ocean.Sci., 19, 183-203, doi: 10.3319/TAO.2008.19.3.183(T). [Link]

Wang, J. H. and B. H. Chin, 1984: Some aspects of microseismicity in the middle part of Taitung Longitudinal Valley and its vicinity. Bull. Inst. Earth Sci.Acad.Sin., 25, 1-11.

Wang, J. H. and R. D. Hwang, 2001: One-dimensional dynamic simulations of slip complexity of earthquake faults. Earth Planets Space, 53, 91-100, doi: 10.1186/ BF03352366. [Link]

Wang, J. H. and C. W. Lee, 1995: Fractal characterization of an earthquake sequence. Physica A, 221, 152-158, doi: 10.1016/0378-4371(95)00270-H. [Link]

Wang, J. H. and C. W. Lee, 1996: Multifractal measures of earthquakes in west Taiwan. Pure Appl. Geophys., 146, 131-145, doi: 10.1007/BF00876673. [Link]

Wang, J. H. and W. H. Lin, 1993: A fractal analysis of earthquakes in west Taiwan. Terr. Atmos. Ocean. Sci., 4, 457-462.

Wang, J. H., Y. B. Tsai, and K. C. Chen, 1983: Some aspects of seismicity in Taiwan region. Bull. Inst. Earth Sci. Acad. Sin., 3, 87-104.

Wang, J. H., T. L. Teng and K. F. Ma, 1989: Temporal variation of coda $Q$ during Hualien earthquake of 1986 in eastern Taiwan. Pure Appl. Geophys., 130, 617-634, doi: 10.1007/BF00881601. [Link]

Wang, J. H., C. H. Hsieh, C. W. Chan, and P. H. Lee, 1990: Seismicity in the Juisui area of eastern Taiwan. Meteorol. Bull. CWB, 36, 197-208. (in Chinese)

Wang, J. H., K. C. Chen, and T. Q. Lee, 1994: Depth distribution of shallow earthquakes in Taiwan. J. Geol. Soc. China, 37, 125-142.

Ward, S. N., 1998: A deficit vanished. Nature, 394, 827829, doi: 10.1038/29639. [Link]

Weeks, J., D. Lockner, and J. Byerlee, 1978: Change in $b$-values during movement on cut surfaces in granite. Bull. Seismol. Soc. Am., 68, 333-341.

Wesnousky, S. G., C. H. Scholz, K. Shimazaki, and T. Matsuda, 1983: Earthquake frequency distribution and the mechanics of faulting. J. Geophys. Res., 88, 93319340, doi: 10.1029/JB088iB11p09331. [Link]

Wesnousky, S. G., C. H. Scholz, K. Shimazaki, and T. Matsuda, 1984: Integration of geological and seismological data for the analysis of seismic hazard: A case study of Japan. Bull. Seismol. Soc. Am., 74, 687-708.

Wiemer, S. and K. Katsumata, 1999: Spatial variability of seismicity parameters in aftershock zones. J. Geophys. Res., 104, 13135-13151, doi: 10.1029/1999JB900032. [Link]

Wiemer, S. and S. R. McNutt, 1997: Variations in the frequency-magnitude distribution with depth in two volcanic areas: Mount St. Helens, Washington, and Mt. Spurr, Alaska. Geophys. Res. Lett., 24, 189-192, doi: 10.1029/96GL03779. [Link]

Wu, F. T., 1978: Recent tectonics of Taiwan. J. Phys. Earth, 26, S265-S299, doi: 10.4294/jpe1952.26.Supplement_ S265. [Link $]$

Wu, Y. H., C. C. Chen, and J. B. Rundle, 2008: Precursory seismic activation of the Pingtung (Taiwan) offshore doublet earthquakes on 26 December 2006: A pattern informatics analysis. Terr. Atmos. Ocean. Sci., 19, 743749, doi: 10.3319/TAO.2008.19.6.743(PT). [Link]

Wu, Y. H., C. C. Chen, D. L. Turcotte, and J. B. Rundle, 2013: Quantifying the seismicity on Taiwan. Geophys. J. Int., 194, 465-469, doi: 10.1093/gji/ggt101. [Link]

Wyss, M. and W. H. K. Lee, 1973: Time variation of the average earthquake magnitude in Central California. Proceedings of the Conference on Tectonic Problems of the San Andreas Fault System, Geological Sciences, XIII, School of Earth Sciences, Stanford University, 24-42.

Wyss, M., F. W. Klein, and A. C. Johnston, 1981: Precursors to the Kalapana $\mathrm{M}=7.2$ earthquake. J. Geophys. Res., 86, 3881-3900, doi: 10.1029/JB086iB05p03881. [Link]

Yamashita, T., 1976: On the dynamical process of fault motion in the presence of friction and inhomogeneous initial stress: Part I. Rupture propagation. J. Phys. Earth, 24, 417-444, doi: 10.4294/jpe1952.24.417. [Link]

Yamashita, T. and L. Knopoff, 1987: Models of aftershock occurrence. Geophys. J. R. astr. Soc., 91, 13-26, doi: 10.1111/j.1365-246X.1987.tb05210.x. [Link]

Yang, C. R., 1986: The present and prospective of earthquake prediction research in the Taiwan region. Natl. Sci. Council Monthly, 14, 1459-1477. (in Chinese)

Yeh, Y. T., 1973: Seismicity in the Jui-sui area. Science Development Monthly, 1, 27-31.

Yeh, Y. T. and P. S. Hsu, 1985: Catalog of earthquakes in Taiwan from 1644 to 1984. Open-file Rept., Inst. Earth Sci., Acad. Sin., Taipei, Taiwan.

Yu, S. B., H. Y. Chen, and L. C. Kuo, 1997: Velocity field of GPS stations in the Taiwan area. Tectonophysics, 274, 41-59, doi: 10.1016/S0040-1951(96)00297-1. [Link] 